\title{
LA REFORMA DEL SISTEMA \\ DE LOS DERECHOS DE AUTOR EN LA UNIÓN EUROPEA. ESTADO DE LA CUESTIÓN
}

\author{
AURELIO LÓPEZ-TARRUELLA MARTÍNEZ*
}

\section{INTRODUCCIÓN}

El presente trabajo tiene como objetivo analizar el estado de la cuestión a noviembre de 2016 del proceso de reforma del sistema de derechos de autor y derechos conexos en la Unión Europea.

Se puede afirmar que dicho proceso, todavía inconcluso, tiene su origen en la "Public Consultation on the Review of the EU Copyright Rules", lanzada por la Comisión Europea a finales de 2013, y el "White Paper on a Copyright Policy for Creativity and Innovation in the European Union", publicado en junio de $2014^{[2]}$. En el segundo semestre de ese año, tras la renovación de sus miembros, la nueva Comisión anunció, como uno de sus objetivo prioritarios, la creación de un mercado único digital. Para la consecución de este objetivo, entre las medidas a adoptar estaba "la modernización de las normas de derechos de autor de acuerdo con las nuevas tecnologías".

Desde entonces, muchas cosas han pasado. Para empezar, en enero de 2015, la europarlamentaria Julia Reda, del Partido Pirata, presentaba su Borrador de

\footnotetext{
* Profesor titular de Derecho Internacional Privado, Universidad de Alicante. Profesor del Magíster Lvcentinvs en Propiedad Industrial e Intelectual (www.ml.ua.es) y de la Maestría en Propiedad Intelectual y Derecho de la Competencia de la Pucp (Lima, Perú). Consultor de distintos organismos internacionales (OMPI, Unión Europea), supervisor en el programa de Doctorado Europeo EIPIN-Is, fundador y director del blog LvCENTINvs (www.lvcentinvs.es), editor de las obras Derecho TIC (Tirant lo Blanch, 2016) y Google and the Law (Springer, 2012) y autor de numerosas publicaciones en el campo de la propiedad intelectual, el comercio electrónico y el derecho internacional privado. Contacto: [Aurelio. Lopez@ua.es]. Fecha de recepción: 15 de octubre de 2016. Fecha de aceptación: 30 de noviembre de 2016. Para citar el artículo: López-Tarruella Martínez, A. La reforma del sistema de los derechos de autor en la Unión Europea. Estado de la cuestión. Revista La Propiedad Inmaterial n.o 22, Universidad Externado de Colombia, julio-diciembre 2016, pp. 101-139. Dor: http://dx.doi.org/10.18601/16571959.n22.07.

1 http://ec.europa.eu/internal_market/consultations/2013/copyright-rules/index_en.htm

2 Del cual nunca se ha publicado un texto oficial, pero han circulado por la red versiones filtradas del borrador; véase: http://ipkitten.blogspot.com.es/2014/06/super-katexclusive-heres-commissions.html
} 
Informe sobre la implementación de la Directiva 2001/29 sobre derechos de autor en la sociedad de la información ${ }^{3}$. Aunque el texto definitivo que se aprobó por el pleno del Parlamento ${ }^{4}$ contiene numerosas modificaciones, la versión inicial generó un pequeño terremoto en Europa al proponer una reforma del sistema del derecho de autor que otorgaba un gran valor al dominio público. En ella incluso se hablaba de reducir el plazo de protección del derecho de exclusividad a 50 años.

En segundo lugar, en mayo de 2015, la Comisión Europea presentó su comunicación "Una Estrategia para el Mercado Único Digital de Europa", en la que desarrollaba sus propuestas para el ya anunciado objetivo de crear un "marco europeo moderno de los derechos de propiedad intelectual”. Con el fin de recabar la opinión de las partes interesadas para elaborar esas propuestas, la Comisión lanzó tres consultas públicas: la consulta "sobre geobloqueo y otras restricciones geográficas a las compras y el acceso a la información", la consulta sobre el "Marco regulador para las plataformas, los intermediarios online, los datos y la computación en la nube y la economía colaborativa en la UE", y la consulta sobre la "Revisión de la Directiva Satélites y Cable"6. A estas tres consultas se les une una última de carácter más general sobre "la evaluación y modernización del marco legal sobre observancia de los derechos de propiedad intelectual"7. Por último, como regalo de Navidad de 2015, la Comisión publicó la propuesta de Reglamento para asegurar la portabilidad transfronteriza de los servicios de contenidos en línea en el mercado interior ${ }^{8}$, y la comunicación "Hacia un marco de derechos de autor moderno y más europeo"9 (en adelante, la Comunicación de 2015), la cual viene acompaña de una nueva consulta ${ }^{10}$.

Lo que llevamos de 2016 ha sido, si cabe, todavía más activo en la materia. Así, en marzo se publicaba una nueva consulta pública sobre la necesidad de regulación a nivel europeo de la excepción a los derechos de autor conocida como "libertad de panorama"11. En mayo veía la luz la propuesta de Directiva

3 Draft Report on the implementation of Directive 2001/29/EC of the European Parliament and of the Council of 22 May 2001 on the harmonisation of certain aspects of copyright and related rights in the information society, disponible en: https://pub. juliareda.eu/copyright_evaluation_report.pdf

4 Resolución del Parlamento Europeo, de 9 de julio de 2015, sobre la aplicación de la Directiva 2001/29/CE del Parlamento Europeo y del Consejo, de 22 de mayo de 2001, relativa a la armonización de determinados aspectos de los derechos de autor y derechos afines a los derechos de autor en la sociedad de la información, disponible en: http://www.europarl.europa.eu/sides/getDoc.do?pubRef=-//EP//TEXT+TA+P8-TA-2OI5$\mathrm{O} 273+\mathrm{O}+\mathrm{DOC}+\mathrm{XML}+\mathrm{VO} / / \mathrm{ES}$

5 Doc. $\operatorname{Cом}(2015) 192$ final.

6 Todas disponibles en: https://ec.europa.eu/digital-single-market/consultations

7 http://ec.europa.eu/growth/tools-databases/newsroom/cf/itemdetail.cfm?item_id=8580

8 Doc. $\operatorname{com}(2015) 627$ final.

$9 \operatorname{Doc} \operatorname{COM}(2015) 626$ final, disponible en: https://ec.europa.eu/transparency/regdoc/ rep/1/2015/ES/1-2015-626-ES-F1-1.PDF

10 Disponible en: http://ec.europa.eu/growth/tools-databases/newsroom/cf/itemdetail. cfm?item_id=8580\&lang=es

$11 \mathrm{https} / /$ ec.europa.eu/digital-single-market/en/news/commission-seeks-views-neighbouring-rights-and-panorama-exception-eu-copyright 
por la que se modifica la Directiva 2010/13 sobre la prestación de servicios de comunicación audiovisual ${ }^{12}$, que vino acompañada de una comunicación titulada "Las plataformas en línea y el mercado único digital. Retos y oportunidades para Europa"13 y de un documento de trabajo que acompaña a esta última comunicación ${ }^{14}$. Pero el "premio gordo" estaba por llegar: en septiembre de 2016 la Comisión Europea presenta la propuesta de Directiva sobre derechos de autor en el mercado único digital ${ }^{15}$, la propuesta de Reglamento por el que se establecen normas sobre el ejercicio de los derechos de autor y derechos afines a los derechos de autor aplicables a determinadas transmisiones en línea de los organismos de radiodifusión y a la retransmisión de programas de radio y televisión ${ }^{16}$; la propuesta de Directiva sobre ciertos usos autorizados de las obras y otras prestaciones protegidas por los derechos de autor y derechos afines a los derechos de autor en beneficio de las personas ciegas, con discapacidad visual o con otras dificultades para acceder al texto impreso ${ }^{17}$, y la propuesta de Reglamento sobre el intercambio transfronterizo entre la Unión y terceros países de ejemplares en formato accesible de determinadas obras y otras prestaciones protegidas por derechos de autor y derechos afines a los derechos de autor en beneficio de las personas ciegas, con discapacidad visual o con otras dificultades para acceder al texto impreso ${ }^{18}$. Estas propuestas legislativas vienen acompañadas de una nueva comunicación titulada "Promover una economía europea basada en los derechos de autor equitativa, eficiente y competitiva en el mercado único digital" (en adelante, la Comunicación de 2016) ${ }^{19}$.

Ante tal aluvión de propuestas legislativas, comunicaciones y documentos de trabajo, parece apropiado analizar en su conjunto cuáles son los objetivos y los rasgos comunes de la reforma que la Comisión Europea propone del sistema de derechos de autor. No nos olvidaremos de la abundante jurisprudencia adoptada por el Tribunal de Justicia de la Unión Europea (TJUE) en los últimos años, por cuanto en ella se ponen de manifiesto los motivos que justifican la reforma -los problemas interpretativos de las directivas en la materia, la incompatibilidad de ciertas prácticas y legislaciones nacionales con los objetivos básicos del proceso de integración europeo- $y$, a su vez, en ella se contienen las bases a partir de las cuales deben elaborarse esas medidas legislativas.

12 Doc. $\operatorname{com}(2016) 287$ final.

13 Doc. $\operatorname{com}(2016) 288$ final.

14 Disponible en: https://ec.europa.eu/digital-single-market/en/news/commission-staffworking-document-online-platforms

15 Doc. $\operatorname{Cом}(2016) 593$ final.

16 Doc. $\operatorname{com}(2016) 594$ final.

17 Doc. сом(2016) 596 final.

18 Doc. $\operatorname{Cом}(2016) 595$ final.

19 Doc. $\operatorname{Com}(2016) 592$ final. 


\section{EN BUSCA DE UN SISTEMA DE DERECHOS DE AUTOR adAPTAdo A LOS OBjetivos DE LA Unión EuRopea}

Como es conocido, la protección de la propiedad intelectual no es un fin en sí mismo para los Estados, sino que es una herramienta que utilizan para impulsar políticas públicas como el desarrollo tecnológico, el fomento de la creatividad y la cultura, o el acceso a la educación. En este sentido, cada Estado otorga el nivel de protección y configura su sistema de propiedad intelectual de acuerdo a sus particulares intereses y condicionamientos.

La Unión Europea no es ajena a esta máxima: su sistema de propiedad intelectual debe adaptarse a los objetivos del proceso de integración europeo. Los objetivos para el decenio 2010-2012 vienen expuestos en la "Estrategia Europa 2020 "20, adoptada por el Consejo de la Unión Europea en 2010. En ese documento se contienen las directrices que deben guiar el modelo económico de la Unión Europea en ese periodo. Tal y como indica la Estrategia, "[e]n un mundo en transformación, queremos que la UE posea una economía inteligente, sostenible e integradora. Estas tres prioridades, que se refuerzan mutuamente, contribuirán a que la UE y sus Estados miembros generen altos niveles de empleo, productividad y cohesión social”.

De especial relevancia para el sistema de propiedad intelectual es el pilar del "crecimiento inteligente", el cual exige realizar inversiones más eficaces en educación, investigación e innovación. Para estimular este crecimiento la Comisión Europea lanzó tres iniciativas emblemáticas, íntimamente relacionadas entre sí. Dos de ellas resultan de especial interés para el campo de la propiedad intelectual. Por un lado, la "Unión por la Innovación"21, en la que se explica la necesidad de fomentar las actividades innovadoras de las empresas europeas para, así, poder competir adecuadamente en los mercados globales. Por otro, la "Agenda Digital para Europa"22, destinada a crear un mercado digital único en la Unión Europea en el que las empresas europeas puedan comercializar sus productos y servicios.

En vista de la primera iniciativa, no es de extrañar el interés de la Unión Europea por garantizar un elevado nivel de protección de la propiedad intelectual tanto en su mercado interior cuanto en los países extranjeros en los que sus empresas hacen negocios. El estudio conjunto de la EPO y la EUIPO (antigua OAMI) de septiembre de 2013 muestra que un 39\% de la actividad económica global de la Unión (cuyo valor asciende a unos 4,7 billones de euros anuales) procede de sectores intensivos en DPI, que generan además de forma directa el $26 \%$ de todos los empleos de la UE (es decir, 56 millones) y, de forma indirecta, el 9\% ${ }^{23}$.

20 Disponible en: http://eur-lex.europa.eu/LexUriServ/LexUriServ. do? uri=COM:2OIO:2O2O:FIN:ES:PDF

21 Disponible en: http://ec.europa.eu/research/innovation-union/index_en.cfm

22 Disponible en: http://ec.europa.eu/information_society/digital-agenda/index_en.htm

$23 \mathrm{OHIM} / \mathrm{EPO}$, Impact of intellectual property rights intensive industries in the European Union, disponible en: https://oami.europa.eu/ohimportal/en/web/observatory/ip-contribution 
Pero una cosa es un sistema que garantice un elevado nivel de protección de la propiedad intelectual, y otra que dicho sistema esté configurado de una manera que garantice la consecución de un mercado digital único. Este segundo objetivo exige llevar a cabo una eliminación de las barreras que obstaculizan que cualquier empresa establecida en un Estado miembro pueda ofrecer sus servicios por medios electrónicos en el resto de Estados miembros; y que dichas empresas puedan ofrecer sus productos y servicios en igualdad de condiciones en ese mercado único digital. Se trata, es preciso recordarlo, de un mercado que englobaría a 28 Estados y con más de 500 millones de potenciales consumidores.

Y aquí es donde empieza el problema. Teniendo en cuenta que la regulación de los derechos de autor sigue estando informada por el principio de territorialidad, con lo que se encuentran las empresas que ofrecen productos o servicios protegidos por estos derechos es con un mercado digital jurídicamente fragmentado en el que resultan aplicables 28 legislaciones diferentes.

Bien es cierto que desde principios de los años 90 se han adoptado gran número de directivas destinadas a armonizar estas legislaciones. No obstante, dichas directivas establecen una armonización de mínimos, por lo que los Estados miembros siempre han tenido libertad para incrementar el nivel de protección de los derechos. Es más, en los últimos años las diferencias se han incrementado con la aparición de nuevos derechos "conexos" como, por ejemplo, la "tasa Google" en España (sobre el particular se habla más adelante); las diferencias regulatorias sobre el derecho de compensación por copia privada; el carácter facultativo del régimen de las excepciones previsto en la Directiva 2001/29 sobre derechos de autor en la sociedad de la información; y el diferente enfoque adoptado a la hora de establecer mecanismos para perseguir la "piratería digital" (la Ley Sinde en España ${ }^{24}$, sistemas de "3-strike you're out" o la Loi HADOPI en Francia $a^{25}$ ). Todo ello genera una gran inseguridad jurídica en aquellas empresas que quieren explotar derechos de autor en una pluralidad de Estados.

Pero además, el principio de territorialidad implica que para poder explotar los derechos de autor sobre una obra en el mercado único digital hay que pedir autorización para cada uno de los Estados miembros en los que se quiere comercializar. Ciertamente, este problema podría solventarse si los titulares de derechos tuvieran la práctica de otorgar licencias multiterritoriales o pan-europeas. Pero esta no es la realidad: son los propios titulares los interesados en "fragmentar" el mercado único para maximizar beneficios. Resulta más rentable otorgar a 28 empresas la licencia para explotar los derechos sobre un determinado contenido en exclusividad para 28 Estados, que a una empresa (o varias en régimen de no exclusividad) para el

24 Nombre que se le dio a la Ley $21 / 2014$, de 4 de noviembre, por la que se modifica el texto refundido de la Ley de Propiedad Intelectual, aprobado por R.D. Legislativo 1/1996, de 12 de abril, y la Ley 1/2000, de 7 de enero, de Enjuiciamiento Civil.

25 Loi n. $2009-669$ du 12 juin 2009 favorisant la diffusion et la protection de la création sur internet. Mas información en: http://www.hadopi.fr/ 
territorio de 28 Estados: resulta más rentable ceder los derechos a 28 entidades en exclusividad para un Estado miembro cada una, que a una o varias para los 28 Estados miembros a la vez. Esta fragmentación del mercado interior supone un perjuicio para las empresas que quieren hacer negocios con contenidos digitales protegidos por propiedad intelectual en el mercado único digital, así como también para los consumidores que, o bien no pueden contratar servicios ofrecidos en otros Estados miembros, o bien no pueden disfrutar de los servicios que han contratado en su Estado miembro de residencia cuando viajan o se mudan a otros Estados miembros. Estas prácticas incluyen el "geoblocking", del cual hablaremos más tarde.

En una dimensión internacional, esta "fragmentación" de los mercados se puede llegar a entender, pero en el marco de un proceso de integración económica como la Unión Europea, asentado en la idea de un mercado interior, resulta difícil de sostener $^{26}$. El sistema de derechos de autor europeo debe incluir mecanismos destinados a acabar con los problemas derivados del principio de territorialidad y, así, permitir que las empresas puedan disfrutar de un verdadero mercado único digital. Esto incluye propuestas, impensables fuera de un proceso de integración como el europeo, como la creación de un título unitario de derechos de autor válido en los 28 Estados, el establecimiento del principio de control en origen combinado con el principio de reconocimiento mutuo, la prohibición del geobloqueo o la profundización en la armonización de las legislaciones estatales mediante directivas.

\section{II. ¿Es Viable El título Unitario De DeRechos De AUTOR EN ESTOS MOMENTOS?}

En su Consulta sobre la revisión del régimen europeo de los derechos de autor ${ }^{27}$, la Comisión Europea explica que la introducción de un título europeo unificado de derechos de autor armonizaría totalmente la materia en la Unión Europea y derogaría las leyes nacionales. Por consiguiente, en vez de un conjunto de derechos nacionales, lo que existiría sería un título único a nivel europeo similar al existente en materia de marca comunitaria y diseño comunitario ( $\mathrm{y}$ hasta cierto punto, la patente con efecto unitario). Para algunos, esta es la única manera de garantizar la existencia de un verdadero mercado único de contenidos protegidos por derechos de autor.

Efectivamente, la introducción de un título unitario de derechos de autor conllevaría grandes beneficios. Entre otros, otorgada una licencia de explotación de derechos, esta tendría validez para toda la UE, no para cada uno de sus Estados. Como es conocido, los títulos unitarios no son nuevos. El artículo 118 Tratado

26 En este sentido, art. 3.3 del Tratado de la Unión Europea: "La Unión establecerá un mercado interior". A su vez, el art. 26.2 del Tratado de Funcionamiento de la Unión Europea: "El mercado interior implicará un espacio sin fronteras interiores, en el que la libre circulación de mercancías, personas, servicios y capitales estará garantizada de acuerdo con las disposiciones de los Tratados".

27 P. 36. 
de Funcionamiento de la Unión Europea ${ }^{28}$ establece una base jurídica clara para llevarlo a cabo mediante el llamado procedimiento legislativo ordinario que exige mayoría cualificada (no unanimidad) en el Consejo. Su adopción supondría una superación por elevación del principio de territorialidad: es decir, este no desaparecería como principio regulador, pero el territorio de referencia pasaría a ser el de la Unión Europea, y no el de cada uno de sus Estados.

La europarlamentaria Julia Reda es una de las defensoras de este título unitario por lo que, en su Borrador de Informe, Reda sugería al Parlamento Europeo apoyar su introducción. No obstante, el texto finalmente adoptado por el pleno del Parlamento se limita a pedir a la Comisión "que estudie el impacto de un título único europeo de los derechos de autor sobre trabajos e innovación, sobre los intereses de los autores, ejecutantes y otros titulares de derechos, y sobre el fomento del acceso de los consumidores a la diversidad cultural regional" ${ }^{29}$.

No es de extrañar que, tras el poco entusiasmo mostrado por el Parlamento, la Comisión haya renunciado a presentar una propuesta en este sentido. Así, en la Comunicación de 2015 se limita a exponer:

... la plena armonización de los derechos de autor en la UE, en la forma de un código de derechos de autor único y de un único título de derechos de autor, exigiría cambios sustanciales en el funcionamiento actual de la normativa. Tendrían que armonizarse ámbitos que hasta el momento se han dejado a la discreción de los legisladores nacionales. La aplicación uniforme de la normativa exigiría una única jurisdicción competente sobre los derechos de autor, con su propio tribunal, de modo que una jurisprudencia incoherente no contribuya a una mayor fragmentación. Esta complejidad no puede justificar la renuncia a esta visión como objetivo a largo plazo. Pese a las particularidades de los derechos de autor y a su relación con las culturas nacionales, las dificultades y los plazos dilatados también acompañaron la creación de títulos únicos y normativas únicas en otros ámbitos de la propiedad intelectual donde hoy son ya una realidad, en particular las marcas y patentes ${ }^{30}$.

En la reciente Comunicación de 2016 ni tan siquiera se menciona.

Se puede afirmar, por ello, que han ganado, por el momento, las ideas de aquellos que ven más fácil conseguir el objetivo de consolidar el mercado único digital mediante el incremento en el nivel mínimo de protección armonizado

28 "En el ámbito del establecimiento o del funcionamiento del mercado interior, el Parlamento Europeo y el Consejo establecerán, con arreglo al procedimiento legislativo ordinario, las medidas relativas a la creación de títulos europeos para garantizar una protección uniforme de los derechos de propiedad intelectual e industrial en la Unión y al establecimiento de regímenes de autorización, coordinación y control centralizados a escala de la Unión.

"El Consejo establecerá con arreglo a un procedimiento legislativo especial, mediante reglamentos, los regímenes lingüísticos de los títulos europeos. El Consejo se pronunciará por unanimidad, previa consulta al Parlamento Europeo".

29 Punto 28.

30 P. 14. 
permitiendo, al mismo tiempo, cierto grado de flexibilidad para que los Estados miembros puedan mantener algunas particularidades en sus sistemas legales.

A mi modo de ver, en el momento actual, esta opción es acertada por cuanto todavía no se dan las bases para la creación de dicho título. Entre otras razones, por las grandes diferencias que existen entre la marca o el diseño y los derechos de autor. Los primeros están basados en el registro, requisito que puede centralizarse ante una oficina como la Euipo. No es el caso de los derechos de autor que, por definición, no están sujetos a formalidad alguna. En segundo lugar, la marca y el diseño comunitarios pueden convivir con títulos nacionales sobre el mismo signo o forma. En derechos de autor esto no tendría sentido. Al contrario de lo que opina la Comisión, no creo que la necesidad de que existiera un tribunal unificado (como ocurre en materia de patente con efecto unificado) fuera un problema, por cuanto se podría adoptar el sistema que rige en materia de marca o diseño comunitario consistente en la creación de tribunales nacionales especializados en el título europeo de derechos de autor. Pero lo más importante es que, al contrario que las marcas y diseños, la creación de un título unitario de derechos de autor supondría una pérdida de competencias de los Estados miembros en una materia que tiene una afectación directa en intereses nacionales muy enraizados: la regulación de los derechos morales o el establecimiento de excepciones que tienen que ver con el acceso a la cultura o a la educación, la investigación, la libertad de expresión, etc.

La opción asumida por la Comisión resulta adecuada: la creación del título unitario debe ser un objetivo a largo plazo al que se debe llegar siguiendo un proceso que exige, a corto-medio plazo, la adopción de medidas de otro tipo, como habilitar mecanismos para facilitar la explotación transfronteriza de los derechos en el mercado único digital, y profundizar en la armonización en materia de derechos de autor para colmar lagunas y hacer frente a cuestiones que el legislador europeo no tuvo (no pudo tener) en cuenta en 2001 cuando adoptó la Directiva 2001/29 sobre derechos de autor en la sociedad de la información (en adelante D. 2001/29).

Además, la historia nos muestra que la creación de un título unitario requiere tiempo. Sin ir más lejos, el proyecto para crear una patente unitaria comenzó en 1962 y, a día de hoy, todavía no ha entrado en vigor. Y cuando lo haga (si es que lo hace, pues el Brexit ha generado una gran incertidumbre) no lo hará para todos los Estados miembros (España decidió no participar en el mismo). En relación con el título unitario de derechos de autor puede afirmarse que la Comisión Europea ha puesto la semilla para su creación. Está por ver lo que tarda en germinar.

\section{EL CONTROL EN ORIGEN Y EL RECONOCIMIENTO MUTUO}

La construcción del mercado interior europeo está basado en el binomio "principio de control en origen-principio de reconocimiento mutuo".

La aplicación de este binomio de principios, en materia de mercancías, significa que, controlada la legalidad de la comercialización de una mercancía en el Estado 
miembro de origen, esta puede comercializarse libremente en el resto de Estados miembros sin que los mismos puedan imponer obstáculos de ningún tipo ${ }^{31}$.

En materia de servicios esto significa que, controlada la legalidad del servicio en el Estado miembro donde está establecido el prestador, el resto de Estados miembros deben reconocer su legalidad y eliminar los obstáculos (incluidos los derivados de divergencias legislativas) para que prestadores de otros Estados miembros puedan prestar sus servicios en su territorio. Así lo explica el TJue en su sentencia de 4 octubre 2011, C-403/08 y C-429/08, "FAPL", sobre la que volveremos más adelante:

El artículo 56 TFUE exige suprimir cualquier restricción a la libre prestación de servicios, aunque se aplique indistintamente a los prestadores de servicios nacionales y a los de los demás Estados miembros, cuando pueda prohibir, obstaculizar o hacer menos interesantes las actividades del prestador establecido en otro Estado miembro, en el que presta legalmente servicios análogos (ap. 85).

La aplicación tal cual de este binomio de principios al suministro de contenidos digitales en soportes tangibles -mercancías- o en línea-servicios- facilitaría enormemente la consolidación del mercado único digital: verificado que el suministro de un contenido digital cumple con la legislación del Estado miembro donde el proveedor tiene su establecimiento, este tiene vía libre para su explotación en el resto de Estados miembros.

Ocurre, sin embargo, que las cosas no son tan sencillas. El TFUE $^{32}$ y la jurisprudencia del TJUE permiten a los Estados miembros establecer o mantener medidas obstaculizadoras de la libre circulación de mercancías y servicios si están justificadas en razones imperiosas de interés general. Y precisamente una de esas razones es la protección de la propiedad intelectual ${ }^{33}$. Ahora bien, al tratarse de una excepción a la regla general (la libre circulación) su interpretación debe ser restrictiva ${ }^{34}$. Es

31 sstjue de 11 de julio de 1974, 8/74, "Dassonville", y 22 de febrero de 1979 , 120/78, "Cassis de Dijon".

32 Art. 36: "Las disposiciones de los artículos 34 y 35 no serán obstáculo para las prohibiciones o restricciones a la importación, exportación o tránsito justificadas por razones de orden público, moralidad y seguridad públicas, protección de la salud y vida de las personas y animales, preservación de los vegetales, protección del patrimonio artístico, histórico o arqueológico nacional o protección de la propiedad industrial y comercial. No obstante, tales prohibiciones o restricciones no deberán constituir un medio de discriminación arbitraria ni una restricción encubierta del comercio entre los Estados miembros".

33 STJUe de 4 de octubre de 2011, "FAPL": "Por lo que respecta a las justificaciones que cabe admitir, de una jurisprudencia reiterada se desprende que tal restricción puede justificarse, en particular, por razones imperiosas de interés general consistentes en la protección de derechos de propiedad intelectual (véanse, en este sentido, las sentencias de 18 de marzo de 1980, "Coditel y otros", "Coditel P", 62/79, Rec. p. 881, apartados 15 y 16, y de 20 de enero de 1981, "Musik-Vertrieb membran y K-tel International", 55/80 y $57 / 80$, Rec. p. 147, apartados 9 y 12)” (ap. 94).

34 sTjue de 4 de octubre de 2011, "FAPL": "una restricción de las libertades fundamentales garantizadas por el Tratado no puede justificarse a menos que responda a razones imperiosas de interés general, que sea adecuada para garantizar la realización del objetivo de interés general que persigue y que no vaya más allá de lo necesario para lograrlo (véase, en este sentido, la sentencia de 5 de marzo de 2009, "UTECA", C-222/07, Rec. p. I-1407, apartado 25 y jurisprudencia citada)" (ap. 93). 
más, la armonización legislativa que se deriva de las directivas en materia de propiedad intelectual tiene como consecuencia indirecta la reducción de las razones imperiosas de interés general que justifican esas restricciones.

En esas directivas y en la jurisprudencia del TJuE se pueden identificar un buen número de manifestaciones particulares de la aplicación del binomio control en origenreconocimiento mutuo en materia de propiedad intelectual. Las propuestas legislativas presentadas por la Comisión en 2016 ahondan en la utilización de esta técnica.

\section{Manifestaciones particulares ya existentes Del binomio CONTrol EN ORIGEN-RECONOCIMIENTO MUTUO EN MATERIA DE PROPIEDAD INTELECTUAL}

La aplicación de este binomio de principios no sólo está previsto en los tratados fundacionales y en la jurisprudencia del TJUE, sino también en directivas, algunas de las cuales se refieren a mercancías y servicios protegidos por derechos de propiedad intelectual.

El principio de agotamiento comunitario -recogido en varias directivas y en la jurisprudencia del TJUE- puede entenderse como una manifestación de este binomio. Así, según la stjue de 21 de junio de 2012, C-5/11, "Titus Donner": "si una obra protegida por derechos de autor es comercializada en un Estado miembro por el titular de dichos derechos o con su consentimiento, tal circunstancia impide a éste oponerse a la libre circulación de la obra en el resto de Estados miembros de la Unión" ${ }^{35}$. Aunque con carácter general, el principio de agotamiento no es aplicable en materia de servicios, incluyendo aquellos que tienen como objeto contenidos protegidos por derechos de autor -sobre el particular, la STJUE de 18 de marzo de 1980, 62/79, "CODITEL $l$ " y el art. 3 D. 2001/29 ${ }^{[36]}$, en la STJue de 3 de julio de 2012, C-128/11, "UsedSoft" el Tribunal sí extendió la aplicación del principio a las licencias de software -calificadas como compraventas- en las que este se descarga de internet, acto que recibe la calificación de "distribución". Más adelante volveremos sobre esta importante decisión.

Además de esta jurisprudencia, también encontramos manifestaciones del binomio control en origen-reconocimiento mutuo en dos instrumentos de la UE que regulan aspectos concretos de los derechos de autor.

35 Debe observarse que en aplicación de jurisprudencia anterior, la decisión puntualiza que no existe agotamiento del derecho "cuando la comercialización no resulta del consentimiento del titular de los derechos de autor, sino de la expiración de sus derechos en un Estado miembro concreto. En este caso, en la medida en que la disparidad de las legislaciones nacionales en materia de duración de la protección puede crear restricciones al comercio en el interior de la Unión, tales restricciones están justificadas en virtud del artículo 36 Tfue, puesto que se derivan de la diferencia de los regímenes, la cual está indisolublemente unida a la existencia misma de los derechos exclusivos". En este sentido, cabe hacer referencia a las Sstjue de 8 de junio de 1971, 78/70, "Deutsche Gramophon", de 20 de enero de 1981, 55/80 y 57/80, "GEMA", y de 24 de enero de 1989, 341/87, "EMI Electrola".

36 Art. 3.3: "Ningún acto de comunicación al público o de puesta a disposición del público con arreglo al presente artículo podrá dar lugar al agotamiento de los derechos a que se refieren los apartados 1 y 2 ". 
En primer lugar, la Directiva 93/83 sobre los derechos de autor en el ámbito de la radiodifusión vía satélite y de la distribución por cable ${ }^{37}$ indica, en su artículo 2:

2. a) A efectos de la presente Directiva se entenderá por "comunicación al público vía satélite" el acto de introducir, bajo el control y la responsabilidad de la entidad radiodifusora, las señales portadoras de programa, destinadas a la recepción por el público en una cadena ininterrumpida de comunicación que vaya al satélite y desde éste a la tierra.

b) La comunicación al público vía satélite se producirá únicamente en el Estado miembro en que, bajo el control y responsabilidad de la entidad radiodifusora, las señales portadoras de programa se introduzcan en una cadena ininterrumpida de comunicación que vaya al satélite y desde éste a la tierra.

Esta disposición implica que, adquirido el derecho de radiodifusión de un contenido audiovisual en el Estado donde se encuentra el organismo de radiodifusión, este puede emitir la señal a cualquier Estado miembro. No se requiere una autorización para cada Estado miembro desde el que se va a recibir la señal.

En segundo lugar, el artículo 4 de la Directiva 2012/28 sobre ciertos usos autorizados de las obras huérfanas establece: "Toda obra o todo fonograma que se consideren obras huérfanas en un Estado miembro, conforme al artículo 2, se considerarán obras huérfanas en todos los Estados miembros. Se permitirá el uso de tales obras o fonogramas y el acceso a ellos de conformidad con la presente Directiva en todos los Estados miembros...”.

Es decir, establecido el carácter de "huérfana" en el Estado miembro de origen de la obra, su estatuto jurídico debe ser reconocido como tal en el resto de Estados miembros y, por tanto, su explotación no puede ser obstaculizada.

\section{Propuestas legislativas Que extienden el binomio control en Origen- RECONOCIMIENTO MUTUO A OTRAS MATERIAS DE PROPIEDAD INTELECTUAL}

Los instrumentos anteriormente analizados ponen de manifiesto que la utilización del binomio principio de control en origen-principio de reconocimiento mutuo ofrece buenos resultados para la consecución del mercado único digital cuando se utiliza para regular cuestiones particulares.

La utilización de este mecanismo legislativo tiene la enorme ventaja de evitar la necesidad de unificar todo el derecho de los Estados miembros. Ciertamente, su introducción genera una "competencia" entre ordenamientos jurídicos en el sentido de que los prestadores de servicios protegidos por derechos de autor deberían buscar establecerse en aquellos Estados miembros cuya legislación en la

37 Directiva 93/83 sobre coordinación de determinadas disposiciones relativas a los derechos de autor y derechos afines a los derechos de autor en el ámbito de la radiodifusión vía satélite y de la distribución por cable. 
materia les resultara más beneficiosa. Si bien sería necesario profundizar más en la cuestión, puede afirmarse que, en la medida en que todas las legislaciones cumplieran con un estándar mínimo de protección fijado por una directiva europea, esta "competencia" entre ordenamientos no debería verse como un problema por cuanto los principales beneficiarios serían los operadores en el tráfico comercial. Es más, esta competencia ya existe en otras materias -en particular, en derecho de sociedades-y la jurisprudencia consolidada del TJUE en la materia no pone ningún tipo de impedimento a la misma.

En cualquier caso, la pregunta que debemos hacer en este momento es otra diferente a la de los beneficios. Resulta preciso abrir una reflexión sobre la viabilidad, a día de hoy, de generalizar la utilización del binomio para la regulación de todos los aspectos de derechos de autor relacionados con los contenidos digitales suministrados en soportes tangibles o en línea.

Un primer intento en esta dirección se hizo con la Directiva 2000/31 sobre comercio electrónico. Como se recordará, su artículo 3 establece:

1. Todo Estado miembro velará por que los servicios de la sociedad de la información facilitados por un prestador de servicios establecido en su territorio respeten las disposiciones nacionales aplicables en dicho Estado miembro que formen parte del ámbito coordinado.

2. Los Estados miembros no podrán restringir la libertad de prestación de servicios de la sociedad de la información de otro Estado miembro por razones inherentes al ámbito coordinado.

De acuerdo con estas disposiciones, si un PSI establecido en España obtiene la autorización para difundir contenidos protegidos por derechos de autor o utiliza dichos contenidos de manera acorde con la legislación de propiedad intelectual española, el resto de Estados miembros no pueden obstaculizar la prestación de dicho servicio aunque el PSI no esté autorizado para la difusión del contenido en ese país por el titular de derechos o por la ley.

Como puede observarse, se trataba de una apuesta muy ambiciosa que hacía primar la consecución de un mercado único digital sobre la competencia de los Estados miembros para adaptar sus normativas de propiedad intelectual a sus intereses nacionales.

Quizás como consecuencia de este exceso de ambición, la propia Comisión Europea acabó reduciendo enormemente el ámbito de aplicación del binomio control en origen-reconocimiento mutuo. Efectivamente, el artículo 3 incluye un apartado 3 que establece: "3. No se aplicarán los apartados 1 y 2 a los ámbitos a que se hace referencia en el anexo".

$\mathrm{El}$ anexo al que se alude incluye como primer punto los "derechos de autor, derechos afines y derechos mencionados en la Directiva 87/54/cee y en la Directiva 96/9/CE, así como a los derechos de propiedad industrial". 
La razón de la exclusión reside en que, en el año 2000, las legislaciones nacionales sobre propiedad intelectual no estaban lo suficientemente armonizadas como para implantar el binomio control en origen-reconocimiento mutuo. Debe recordarse que en dicho momento todavía se estaba negociando la D. 2001/29.

Pero, mucho ha llovido en materia de propiedad intelectual desde el año 2000: varias directivas han sido adoptadas, varios tratados internacionales se han ratificado -la UE se adhirió a TODA, TOIEF en 2010- y multitud de sentencias del TJUE han interpretado dichos instrumentos. ¿Puede entenderse que gracias a todo esto se ha alcanzado el nivel de armonización necesario para adoptar el binomio con carácter general? En opinión de la Comisión Europea, si bien no es posible adoptar el binomio con carácter general, sí es posible extender su aplicación a otros aspectos de la propiedad intelectual. Así lo demuestran las propuestas recientemente presentadas en relación con los servicios accesorios en línea de organismos de radiodifusión y distribución por cable; la utilización de obras y otras prestaciones en actividades pedagógicas digitales $\mathrm{y}$ transfronterizas; $\mathrm{y}$ el intercambio transfronterizo de ejemplares de obras en formato accesible para personas con discapacidad visual.

\section{a. Servicios accesorios en línea prestados por organismos de radiodifusión $y$ distribución por cable}

La "Consulta sobre la revisión de la Directiva 93/83 sobre los derechos de autor en el ámbito de la radiodifusión vía satélite y de la distribución por cable” proponía extender el ámbito de aplicación de la Directiva a programas de radio y televisión que se ofrecen a través de internet.

La propuesta de Reglamento sobre transmisiones en línea de los organismos de radiodifusión y a las retransmisiones de programas de radio y televisión confirma esta solución. De acuerdo con su artículo 2 -titulado concretamente Aplicación del principio del "pais de origen" a los servicios accesorios en línea-:

1. A efectos del ejercicio de los derechos de autor y derechos afines pertinentes, se considerará que los actos de comunicación al público y de puesta a disposición que se producen cuando se presta un servicio accesorio en línea por parte de un organismo de radiodifusión, o bajo su control y responsabilidad, así como los actos de reproducción que sean necesarios para la prestación, el acceso o la utilización del servicio accesorio en línea, se han producido únicamente en el Estado miembro en el que el organismo de radiodifusión tiene su establecimiento principal.

$\mathrm{Al}$ indicar que debe entenderse que el servicio accesorio en línea se ha producido únicamente en el Estado miembro en el que el organismo de radiodifusión tiene su establecimiento principal, la propuesta indica que su licitud se regula por la ley del Estado de origen del servicio. Las autoridades de los Estados miembros desde los que se recibe el servicio no pueden aplicar su ley para verificar su legalidad. Tan 
sólo podrán aplicar la ley del Estado de origen, pues allí es donde tiene lugar la presunta infracción. Es decir, deben limitarse a reconocer la legalidad del servicio si cumple con los requisitos del Estado de origen.

Debe señalarse que en paralelo a la consulta sobre la Directiva 93/83 también se abrió otra sobre la revisión de la Directiva 2010/13 de servicios de comunicación audiovisual ${ }^{38}$. Esta Directiva permite que -con algunas excepciones- las empresas que cumplen con los requisitos legales del Estado miembro donde están establecidos presten sus servicios en todo el mercado ue. En la actualidad la Directiva es aplicable a organismos de radiodifusión y organismos que prestan servicios por demanda por internet como Netflix, pero no a PSI que albergan el llamado "User Generated Content" (como YouTube o Vimeo) o a sitios web como los de los periódicos que albergan videos cortos sobre noticias de actualidad (sTJUe 21 de octubre de 2015, C-347/14, "New media online"). En la consulta se preguntaba si el régimen de la Directiva debería extenderse también a estos servicios. Esta extensión estaría además justificada en el grado de convergencia que están adquiriendo estos servicios: los organismos de radiodifusión no se limitan a ofrecer sus programas por televisión sino que con carácter general también lo ofrecen a través de sus sitios web y aplicaciones móviles.

Finalmente, la Comisión se ha decantado por esta opción en la propuesta de Directiva por la que se modifica la Directiva 2010/13. Para ello se ha insertado una letra a bis) en su artículo 1, que extiende el ámbito de aplicación de la Directiva a los servicios de plataforma de distribución de vídeos, entendidos como aquellos que cumplen los siguientes requisitos:

i) el servicio consiste en el almacenamiento de una gran cantidad de programas o vídeos generados por los usuarios, cuya responsabilidad editorial no recae sobre el proveedor de la plataforma de distribución de vídeos;

ii) la organización de los contenidos almacenados está determinada por el prestador del servicio, incluso por medios o algoritmos automáticos, en particular mediante el alojamiento, la presentación, el etiquetado y la secuenciación;

iii) la finalidad principal del servicio o de una de sus partes disociables es ofrecer programas y vídeos generados por los usuarios al público en general, con objeto de informar, entretener o educar;

iv) el servicio se presta a través de redes de comunicaciones electrónicas, en el sentido de la letra a) del artículo 2 de la Directiva 2002/21/CE. 
De acuerdo con el considerando 3 resultan incluidos dentro de esta definición aquellos psi cuyo objetivo principal es suministrar estos contenidos con el fin de informar, entretener o educar (sería el caso de YouTube, Vimeo o Dailymotion). En principio no resultan aplicables a sitios web cuya finalidad principal no sea esa, tales como publicaciones digitales o redes sociales, salvo que estos sitios web contengan una parte disociable de su actividad principal que persiga esta finalidad.

Como servicios de comunicación audiovisual que son, las plataformas de distribución de videos están sujetas al principio de control en origen, tal y como establece el artículo 2: "Los Estados miembros velarán por que todos los servicios de comunicación audiovisual transmitidos por prestadores del servicio de comunicación bajo su jurisdicción respeten las normas del ordenamiento jurídico aplicables a los servicios de comunicación audiovisual destinados al público en dicho Estado miembro".

Ahora bien, una vez autorizada la prestación del servicio en el Estado de origen, estas plataformas disfrutan de la libertad de prestación de servicios en el sentido del artículo 3: "Los Estados miembros garantizarán la libertad de recepción y no obstaculizarán las retransmisiones en su territorio de servicios de comunicación audiovisual procedentes de otros Estados miembros por motivos inherentes a los ámbitos coordinados por la presente Directiva”.

Si bien el ámbito coordinado de la Directiva 2010/13 no incluye aspectos de propiedad intelectual, es interesante observar que su propuesta de modificación va de la mano de la propuesta de Reglamento sobre transmisiones en línea de los organismos de radiodifusión. Primero, porque ambas extienden el ámbito de aplicación de sus disposiciones a las actividades online de estos operadores. Segundo, porque el mecanismo de regulación de ambas está basado en el binomio control en origen-reconocimiento mutuo: si el contenido es lícito de acuerdo con el Estado miembro de origen, el resto de Estados miembros no pueden establecer obstáculos a su recepción.

\section{b. Utilización de obras y otras prestaciones en actividades pedagógicas digitales $y$ transfronterizas}

Como es conocido, las legislaciones de derechos de autor regulan con carácter general el uso de las obras con fines de ilustración en la enseñanza como una excepción al derecho de autor. Como veremos en el apartado III, la Comisión se propone establecer un régimen uniforme de esta excepción a nivel europeo.

Pero, a efectos de este apartado, resulta preciso destacar el artículo 4.3:

Se considerará que el uso de obras y otras prestaciones únicamente con fines ilustrativos de enseñanza a través de redes electrónicas seguras hecho en cumplimiento de las disposiciones de Derecho nacional adoptadas en virtud del presente artículo únicamente tiene lugar en el Estado miembro en que está establecido el centro de enseñanza. 
Se trata de otra manifestación del binomio control en origen-reconocimiento mutuo en el que se utiliza una fórmula similar a la establecida en la Directiva 93/83 y la propuesta de Reglamento sobre transmisiones en línea de los organismos de radiodifusión. La legalidad de la utilización de la obra se juzga únicamente en atención a la normativa del Estado miembro donde se encuentra el establecimiento del centro de enseñanza -país de origen-. Independientemente de los Estados miembros donde están localizados los estudiantes, la utilización de la obra será considerada lícito.

De esta manera se soluciona el problema de falta de seguridad jurídica que tienen actualmente los servicios de enseñanza online transfronterizos: si bien la legislación donde se encuentra el centro de enseñanza puede permitir el uso de la obra en sus cursos, las legislaciones de los países donde se encuentran los estudiantes pueden ofrecer una respuesta diferente. La propuesta elimina este problema: la legalidad del uso de los materiales se juzga exclusivamente en atención a la legislación del Estado miembro de origen.

Esta solución puede suponer una concentración de los centros de enseñanza online en Estados miembros que ofrezcan un menor nivel de protección de las obras. Esto no debería ser así pues el artículo 4 garantiza una regulación uniforme de la excepción. No obstante, pueden existir otros elementos adicionales que condicionen esta respuesta. En particular, porque la disposición ofrece cierta flexibilidad a los Estados miembros a la hora de exceptuar la aplicación de la excepción para ciertas categorías de obras y establecer un sistema de remuneración de los titulares de derechos (art. 4.2 y 4). No obstante, según se ha indicado anteriormente, la competencia entre ordenamientos no es preocupante en la medida en que se cumplan unos estándares mínimos de protección.

\section{c. El Tratado de Marrakech y el intercambio transfronterizo de ejemplares de obras en formato accesible para personas con discapacidad visual}

La Unión Europea ha anunciado su intención de ratificar el Tratado de Marrakech para facilitar el acceso a las obras publicadas a las personas ciegas, con discapacidad visual o con otras dificultades para acceder al texto impreso ${ }^{39}$. Como es conocido, dicho tratado acaba de entrar en vigor para los 22 Estados que hasta septiembre de 2016 lo habían ratificado.

La ratificación por parte de la Unión Europea no debería presentar mayores obstáculos. Más aún si, como ya ha afirmado el Abogado General, el Tribunal de 
Justicia confirma que la competencia exclusiva para su ratificación corresponde a las instituciones europeas y no a los Estados miembros ${ }^{40}$.

Para que esta ratificación sea posible es preciso adaptar la legislación europea de derechos de autor al contenido del Tratado. Así, se han presentado una propuesta de directiva que establece una excepción al derecho de autor que permite la realización de ejemplares de las obras en formato accesible para personas con discapacidad visual, y una propuesta de reglamento que garantiza el intercambio transfronterizo de esos ejemplares entre los Estados contratantes del Tratado.

Este último instrumento tiene como finalidad implementar en el derecho de la UE los artículos 5 y 6 del Tratado de Marrakech. Dichas disposiciones establecen un mecanismo relativo a la exportación-importación de ejemplares de la obra en formato accesible que se asemeja a este binomio de principios.

Así, al principio de control en origen se refiere el artículo 5.1 cuando establece:

1. Una Parte Contratante dispondrá que, si un ejemplar en formato accesible es realizado en virtud de una limitación o de una excepción o por ministerio de la ley, ese ejemplar en formato accesible podrá ser distribuido o puesto a disposición por una entidad autorizada a un beneficiario o a una entidad autorizada en otra Parte Contratante.

Por su parte, el principio de reconocimiento mutuo vendría recogido en el artículo 6:

En la medida en que la legislación nacional de una Parte Contratante permita a un beneficiario, a alguien que actúe en su nombre o a una entidad autorizada realizar un ejemplar en formato accesible de una obra, la legislación nacional de esa Parte Contratante les permitirá también importar un ejemplar en formato accesible destinado a los beneficiarios, sin la autorización del titular de los derechos.

Con estas disposiciones se persigue que una autoridad autorizada que ha realizado copias de un ejemplar en formato accesible de acuerdo con la legislación prevista en su país de origen, pueda distribuir dichos ejemplares a entidades autorizadas de otro Estado contratante para que estas puedan distribuir estas copias entre los beneficiarios de ese país. La legislación de ese segundo Estado no puede obstaculizar dicha importación.

Para dar cumplimiento al Tratado de Marrakech, el artículo 3 de la propuesta de Reglamento establece:

Las entidades autorizadas establecidas en un Estado miembro podrán distribuir, difundir o poner a disposición de los beneficiarios o entidades autorizadas de terceros países que sean parte en el Tratado de Marrakech ejemplares en formato accesible realizados de conformidad con la legislación nacional adoptada con arreglo a la Directiva...

40 Conclusiones del Abogado General de 8 de septiembre de 2016, Dictamen 3/15, "Tratado de Marrakech". 
Por su parte, el artículo 4 indica:

Los beneficiarios y las entidades autorizadas establecidas en un Estado miembro podrán importar, o conseguir o adquirir por cualquier otra vía, y por tanto utilizar, de conformidad con la legislación nacional adoptada en virtud de lo previsto en la Directiva [...], ejemplares en formato accesible distribuidos, difundidos o puestos a disposición de los beneficiarios o las entidades autorizadas por parte de una entidad autorizada en un tercer país que sea parte en el Tratado de Marrakech.

Como puede observarse, en este caso se propone una utilización del binomio control en origen-reconocimiento mutuo no sólo para situaciones intra-UE (intercambio de ejemplares de un Estado miembro a otro) sino también extra-UE (intercambio entre un Estado miembro y un tercer Estado contratante del Tratado de Marrakech), lo cual supone una interesante novedad.

\section{LA PROHIBICIÓN DEL GEOBLOQUEO Y LAS PRÁCTICAS DE COMPARTIMENTACIÓN DEL MERCADO}

Según se ha indicado en el apartado I, la compartimentación del mercado único digital que se deriva del principio de territorialidad se manifiesta en dos sentidos.

Por un lado, la negociación de licencias por parte de los titulares de los derechos para la explotación de las obras se realiza Estado por Estado. Así, si una organismo de televisión quiere adquirir los derechos para emitir una película en dos o más Estados miembros debe adquirir tantas licencias como Estados miembros en los que quiere operar, y pueden encontrarse con que la licencia para emitir la película en un Estado diferente al de su establecimiento ya se haya otorgado a un organismo que opera en ese país. Como hemos dicho en el apartado I, esto no debería ser necesariamente así, por cuanto nada impide a los titulares de derechos otorgar a un mismo operador licencias para varios Estados a la vez, o licencias pan-europeas. No obstante, resulta mucho más rentable licenciar los derechos Estado por Estado. Así, por ejemplo, Netflix ha estado disponible en distintos Estados miembros desde hace tiempo, pero hasta octubre de 2015, fecha en la que obtuvo las licencias necesarias, no empezó a operar en España. Y cuando empezó a operar fue sin la posibilidad de ofrecer la última temporada de su serie emblemática, Houses of Cards, por cuanto los derechos sobre la misma ya los tenía otro operador.

Por otro lado, la compartimentación del mercado provoca que los usuarios sólo puedan acceder a los servicios ofrecidos por los organismos de radiodifusión de su Estado de residencia. Efectivamente, un usuario residente en España no puede contratar el servicio ofrecido por Netflix en Francia o en el Reino Unido. Es más, cuando cualquiera de los usuarios de Netflix en Francia viaja a otro Estado miembro, tampoco podría disfrutar del servicio contratado. Esta circunstancia resulta 
incomprensible para los usuarios por su contrariedad con la idea de un mercado único digital, y además fomenta el recurso a la piratería o a técnicas ilegales de "rodeo" a través de redes privadas virtuales (VPN).

En relación con esta compartimentación del mercado único digital es preciso referirse a tres actuaciones concretas.

La primera es la introducción de sistemas de licencias multiterritoriales a partir de la Directiva 2014/26 relativa a la gestión colectiva de los derechos de autor y derechos afines y a la concesión de licencias multiterritoriales de derechos sobre obras musicales para su utilización en línea en el mercado interior (en adelante D. 2014/26). En sus recientes propuestas, la Comisión Europea propone extender este sistema a otros ámbitos.

La segunda y la tercera son respectivamente la adopción por el Tribunal de Justicia de la sentencia de 4 de octubre de 2011, “FAPL", y la reciente publicación por la Comisión Europea de la propuesta de Reglamento por el que se garantiza la portabilidad transfronteriza de los servicios de contenidos en línea en el mercado interior ${ }^{41}$.

\section{Sistemas DE LICENCIAS MULTITERRITORIALES DE DERECHOS}

De acuerdo con la Directiva 2014/26, los titulares de derechos sobre obras musicales tiene derecho a elegir "la entidad de gestión colectiva encargada de gestionar sus derechos respecto de los territorios de su elección, independientemente de la nacionalidad o del Estado miembro de residencia o de establecimiento de la entidad de gestión colectiva o del titular de derechos" (art. 5.2). De esta manera, si un proveedor de servicio de música en streaming (p. ej., Spotify) quiere adquirir los derechos para ofrecer las canciones de un determinado grupo musical a sus usuarios de los Estados miembros donde ofrece su servicio, basta con que solicite una única licencia a la entidad encargada de la gestión de dichos derechos. No es preciso, como en otros casos, adquirir los derechos para cada Estado miembro de la entidad encargada de la gestión de los derechos en dicho Estado miembro. Se elimina así el problema derivado de la fragmentación del mercado único.

Este sistema de licencias multiterritoriales sirve de base para la regulación en los artículos 7 a 9 de la propuesta de Directiva sobre derechos de autor en el mercado único digital de las licencias de uso de obras fuera del circuito comercial por parte de instituciones de patrimonio cultural.

La regulación tiene como finalidad favorecer la difusión del legado cultural europeo y sus destinatarios son, únicamente, las instituciones de patrimonio cultural (bibliotecas, museos, archivos o instituciones responsables del patrimonio cinematográfico o sonoro). 
El artículo 8.1 indica que la licencia de uso adquirida por una institución de patrimonio cultural de una entidad de gestión colectiva de un determinado Estado miembro para la digitalización y explotación de una obra fuera del circuito comercial (aquella que no está a disposición del público a través de los canales comerciales habituales y que no pueda esperarse razonablemente que lo esté) se extiende a todos los Estados miembros. Es decir, se exime a la institución que quiere poner la obra a disposición del público en toda la UE de ir adquiriendo licencias Estado por Estado. Bastará con que adquiera una licencia de una sola entidad de gestión (en particular, la designada en atención a los criterios del art. 7.4).

Se puede criticar que el impacto práctico de esta nueva propuesta es inferior al de la D. 2014/26, pero es una muestra más de la voluntad firme de la Comisión Europea por acabar con la fragmentación del mercado único.

\section{Las implicaciones de LA STJUe De 4 De OCTUbRe De 2OII, "FapL" PARA EL SUMINISTRO DE CONTENIDOS DIGITALES PROTEGIDOS POR DERECHOS DE PROPIEDAD INTELECTUAL EN EL MERCADO ÚNICO DIGITAL}

Los hechos que dieron lugar a la STJUe de 4 de octubre de 2011, "FAPL" son los siguientes: la Football Association Premier League (FAPL) otorga licencias para emitir los partidos de la Liga inglesa de fútbol (Premier League) siguiendo el esquema anteriormente descrito, es decir, país por país. En dichas licencias impone una obligación a los licenciatarios de adoptar las medidas necesarias para que la emisión no se pueda ver fuera del territorio de ese país. En particular, cada organismo debe actuar de manera que todas las emisiones suyas que puedan ser captadas fuera de dicho territorio - en particular, las que se emiten vía satélite- estén codificadas de manera segura.

El litigio aparece cuando los abogados de la Premier League observan que algunos establecimientos de restauración en el Reino Unido comenzaron a utilizar decodificadores extranjeros para acceder a los partidos de la Premier League. Dichos establecimientos compraban a un distribuidor una tarjeta y un decodificador que permitían la recepción de un canal vía satélite emitido en otro Estado miembro -en concreto, un canal griego-, cuyo abono es más ventajoso que el abono del canal británico que tiene los derechos para ese país.

El TJUE en su decisión comienza por afirmar que las limitaciones territoriales impuestas por las licencias e implementadas tecnológicamente mediante los codificadores son medidas que obstaculizan a los organismos de radiodifusión griegos prestar sus servicios en otros Estados miembros (en concreto, en el Reino Unido).

Como se ha dicho, tales obstáculos pueden justificarse en "razones imperiosas de interés general", entre las que, según se ha explicado, se encuentra la protección de la propiedad intelectual. En opinión de la FAPL, estas limitaciones territoriales son necesarias "para garantizar la protección de la remuneración 
adecuada de dichos titulares". En particular, la FAPL indica que de no imponerse esas limitaciones,

... el titular de derechos de propiedad intelectual no estaría ya en condiciones de obtener los cánones adecuados de licencia por parte de los organismos de radiodifusión, dado que la difusión en directo de encuentros deportivos habría perdido parte de su valor. Efectivamente, los organismos de radiodifusión no estarían interesados en la adquisición de licencias fuera del territorio del Estado miembro de emisión. Una adquisición de licencias para todos los territorios nacionales en los que residen clientes potenciales no resulta interesante desde el punto de vista financiero, debido al precio extremadamente alto de dichas licencias. Por tanto, esos organismos adquieren las licencias para emitir las obras en cuestión en el territorio de un único Estado miembro. Pues bien, están dispuestos a pagar un suplemento importante con la condición de tener la garantía de exclusividad territorial porque ésta les permite diferenciarse de sus competidores y atraer de ese modo a más clientes.

El TJUE no consideró aceptables los argumentos de la FAPL por cuanto las restricciones a la libre prestación de servicios no puede ir más allá de lo necesario para lograr el objetivo de protección de la propiedad intelectual. Una cosa es adoptar medidas para asegurar a los titulares de derechos afectados la protección de la facultad de explotar comercialmente la obra -lo cual es aceptable-, y otra es adoptar medidas para garantiza a los titulares de derechos afectados la posibilidad de reclamar la máxima remuneración posible. Esto segundo no es aceptable cuando la medidas adoptadas están destinadas a garantizar una exclusividad territorial absoluta que puede provocar diferencias de precio artificiales entre los mercados nacionales compartimentados. Tal compartimentación y la diferencia artificial de precio que de ella resulta son incompatibles con el objetivo esencial del Tratado, que es la realización del mercado interior.

Por otra parte, el TJuE también consideró que las cláusulas de los contratos de licencia exclusiva celebrados entre un titular de derechos de propiedad intelectual y un organismo de radiodifusión constituían una restricción de la competencia prohibida por el derecho europeo en la materia puesto que su finalidad es la compartimentación de los mercados nacionales y dificultar o impedir la interpenetración de dichos mercados por operadores de otros Estados miembros.

Las implicaciones de la STJUE de 4 de octubre de 2011, "FAPL" son considerables por cuanto con ella se abre la puerta a que los organismos de radiodifusión ofrezcan sus contenidos a usuarios residentes en otros Estados miembros. Ciertamente estos no van a ser una mayoría por cuanto los contenidos que interesan a un público u otro son diferentes por razones culturales o lingüísticas, pero la decisión supone un gran paso para la consolidación de un mercado digital único.

En la medida en que los grandes estudios de Hollywood han hecho oídos sordos a esta decisión y siguen imponiendo restricciones territoriales absolutas a los organis- 
mos de radiodifusión que adquieren derechos para difundir sus películas, en 2014 la Comisión Europea abrió una investigación por prácticas anticompetitivas ${ }^{42}$ que ha derivado en la apertura de un procedimiento sancionador en julio de $2015^{[43]}$.

Ahora bien, no resulta del todo claro que la utilización de estas restricciones territoriales sea siempre anticompetitiva. Debe examinarse caso por caso. De hecho, en su pliego de cargos enviados a las partes interesadas en estos procedimientos, la Comisión se refiere a ilegalidad de prohibir las "ventas pasivas" (aquellas en las que es el usuario el que va buscando al prestador localizado en otro Estado para contratar sus servicios, y no a la inversa). Es decir, la prohibición de las "ventas activas" (aquellas en las que es el prestador el que ofrece sus servicios en el Estado miembro de residencia del consumidor) seguiría estando permitida.

Además, de ser posible que los organismos de radiodifusión pudieran prestar sus servicios de contenidos audiovisuales a usuarios de otros Estados miembros todavía persistiría un cuestión problemática: si el operador sólo tiene la licencia para explotar los derechos en el Estado miembro de establecimiento, ¿cómo va a poder ofrecer sus servicios a usuarios que residen en otros Estados miembros sin que se produzca una infracción de derechos? Algunos hablan, incluso, de que los pliegos de cargos enviados por la Comisión en los procedimientos anteriormente mencionados sólo se entienden si la Comisión está pensando en abrir la puerta al principio de agotamiento del derecho de comunicación pública a nivel europeo ${ }^{44}$.

\section{La propuesta de Reglamento sobre "Geobloqueo"}

El tercer acontecimiento a reseñar está referido a la situación de los usuarios, los cuales, por culpa del "geobloqueo" que imponen los organismos de radiodifusión, no pueden disfrutar en otros Estados miembros de los servicios que han contratado en su Estado miembro de residencia. Para luchar contra esta práctica, la Comisión Europea publicó en diciembre de 2015 la propuesta de Reglamento por el que se garantiza la portabilidad transfronteriza de los servicios de contenidos en línea en el mercado interior. En el momento actual, la propuesta está siendo discutida en el Consejo, y no se espera una votación en primera lectura por parte del Parlamento hasta enero de 2017.

Su artículo 3 establece que el prestador de un servicio de contenidos en línea debe hacer posible que el abonado que se encuentre presente temporalmente en un Estado miembro diferente al de su residencia habitual pueda acceder al servicio de contenidos en línea y utilizarlo.

42 "Antitrust: Commission investigates restrictions affecting cross border provision of pay TV services”, disponible en: http://europa.eu/rapid/press-release_IP-14-15_en.htm

43 "Antitrust: Commission sends Statement of Objections on cross-border provision of pay-TV services available in UK and Ireland", disponible en: http://europa.eu/rapid/ press-release_IP-15-5432_en.htm

44 "Copyright reform through competition law? The Commission's statement of objections in the pay TV investigation", disponible en: https://ipkitten.blogspot.com. es/2015/07/copyright-reform-through-competition.html 
Asimismo, de acuerdo con el artículo 5 se consideran nulas de pleno derecho las cláusulas incluidas en los contratos celebrados entre los titulares de derechos y los prestadores de contenidos, o entre estos últimos y los usuarios que impida este acceso y utilización al servicio.

Para evitar que la explotación de los derechos de autor que implica este acceso y utilización se pueda considerar como una infracción -por no estar cubierta por la licencia de derechos otorgada- el artículo 4 indica que "la prestación de un servicio de contenidos en línea, así como el acceso al servicio y su uso por parte de un abonado de conformidad con el artículo 3, apartado 1, se produce únicamente en el Estado miembro de residencia".

La propuesta debe ser bienvenida por los beneficios que conlleva para impulsar el mercado único digital. Ahora bien, la misma presenta una duda relativa al concepto de "presencia temporal" pues la definición aportada es muy escueta: "la presencia de un abonado en un Estado miembro distinto de su Estado miembro de residencia". ¿Puede entenderse que "presencia temporal" se limita a un par de días? ¿O están los prestadores de estos servicios obligados a impedir el "geobloqueo" cuando la presencia es de dos semanas, un mes o, incluso, 6 meses?

\section{Profundizar en la armonización}

Ante la imposibilidad por el momento de crear un título unitario de derechos de autor, y las limitaciones del binomio control en origen-reconocimiento mutuo y de las soluciones aportadas a la compartimentación del mercado único digital, resulta imprescindible acudir al mecanismo tradicional, es decir, la armonización de las legislaciones nacionales.

Aunque pudiera pensarse que la armonización resulta menos compleja que el resto de mecanismos analizados, la tarea no es nada fácil. Las consultas realizadas ponen de manifiesto la existencia de intereses enfrentados: mientras editores, autores y entidades de gestión colectiva abogan por incrementar la protección de los derechos; las asociaciones representantes de los usuarios finales y de las instituciones (bibliotecas, universidades, museos, archivos) abogan por una reforma del sistema que ponga en valor el dominio público.

La necesidad de abrazar todos los intereses en presencia ha llevado a la Comisión Europea a anunciar que el objetivo de la reforma debe ser el de

... conseguir una amplia disponibilidad de los contenidos creativos en toda la UE, garantizar que la normativa sobre derechos de autor de la UE siga proporcionando un alto nivel de protección a los titulares de derechos y mantener un equilibrio adecuado con otros objetivos de política pública, como la educación, la investigación y la innovación o la igualdad de acceso para las personas con discapacidad, en el entorno digital ${ }^{45}$. 
De acuerdo con este objetivo, la Comisión ha centrado sus esfuerzos en cuatro áreas: los derechos exclusivos, las relaciones contractuales de los autores, las excepciones a dichos derechos y los medios de defensa de estos. Las dos primeras áreas son abordadas en la propuesta de Directiva de derechos de autor en el mercado único digital y la propuesta de Directiva sobre determinados usos permitidos de obras y otras prestaciones protegidas por derechos de autor en favor de personas con discapacidad visual. Como explica la Comisión en su Comunicación de 2016 ${ }^{[46]}$, la tercera será objeto de propuestas legislativas en un futuro no muy lejano.

\section{Derechos exclusivos}

Un requisito imprescindible para el buen funcionamiento del mercado de los derechos de autor es la posibilidad de que los titulares de los derechos concedan licencias y sean remunerados por la utilización de sus contenidos, incluidos los distribuidos en línea.

Resulta indiscutible que cualquier tipo de explotación de una obra en el entorno digital precisa de la autorización del autor salvo, claro está, que el acto de explotación esté amparado en una excepción al derecho de exclusividad.

Los avances tecnológicos y la aparición de nuevos modelos de negocio en el entorno digital han generado dudas, entre otros aspectos, en relación a los servicios de agregación de noticias, la utilización de hipervínculos y el agotamiento "digital" del derecho. De estos tres aspectos, la Comisión Europea ha decidido actuar únicamente en relación con el primero. Sin embargo, los otros dos han sido objeto de varias sentencias del tJuE que es necesario reseñar.

\section{a. Servicios de agregación de contenidos}

Los servicios de agregación de contenidos y, en particular, de noticias (el ejemplo paradigmático es el de Google News) están en el punto de mira de las instituciones desde hace tiempo. Los medios de comunicación consideran que estos servicios hacen dinero a consta de los contenidos proporcionados por otros y, además, les generan pérdidas por cuanto estos agregadores provocan que para acceder a los contenidos, los usuarios ya no tengan que pasar por la página principal del sitio web en cuestión, circunstancia que conlleva una merma en los ingresos por publicidad.

Los agregadores se defienden afirmando que gracias a sus servicios se incrementa el tráfico de los sitios web de los medios de prensa.

Esta disputa se ha extendido a varios Estados: Bélgica, donde, tras una decisión judicial en su contra, Google News dejó de listar los medios de comunicación de ese país; Francia, donde Google llegó a un acuerdo con los periódicos locales para poder indexar sus contenidos; Alemania, donde se ha adoptado legislación para 
proteger los intereses de los medios de comunicación, si bien las últimas noticias apuntan a una nueva demanda contra Google ${ }^{47}$; y España, donde tras el establecimiento de un nuevo derecho conexo relativo al uso de contenidos en los índices de estos servicios de agregación (la llamada "tasa Google"), Google News dejó de operar y otros servicios similares cerraron sus puertas.

En particular, en España, el nuevo artículo 32.2, vigente desde el 1 de enero de 2015, establece:

2. La puesta a disposición del público por parte de prestadores de servicios electrónicos de agregación de contenidos de fragmentos no significativos de contenidos, divulgados en publicaciones periódicas o en sitios Web de actualización periódica y que tengan una finalidad informativa, de creación de opinión pública o de entretenimiento, no requerirá autorización, sin perjuicio del derecho del editor o, en su caso, de otros titulares de derechos a percibir una compensación equitativa. Este derecho será irrenunciable y se hará efectivo a través de las entidades de gestión de los derechos de propiedad intelectual. En cualquier caso, la puesta a disposición del público por terceros de cualquier imagen, obra fotográfica o mera fotografía divulgada en publicaciones periódicas o en sitios Web de actualización periódica estará sujeta a autorización.

Sin perjuicio de lo establecido en el párrafo anterior, la puesta a disposición del público por parte de prestadores de servicios que faciliten instrumentos de búsqueda de palabras aisladas incluidas en los contenidos referidos en el párrafo anterior no estará sujeta a autorización ni compensación equitativa siempre que tal puesta a disposición del público se produzca sin finalidad comercial propia y se realice estrictamente circunscrita a lo imprescindible para ofrecer resultados de búsqueda en respuesta a consultas previamente formuladas por un usuario al buscador y siempre que la puesta a disposición del público incluya un enlace a la página de origen de los contenidos.

Debido al peligro que conlleva para la consolidación del mercado único digital que la regulación de las actividades de estos servicios de agregación se esté realizando de manera diferente de un Estado miembro a otro, la Comisión Europea anunció en la Comunicación de 2015 que estudiaría "la conveniencia de medidas específicas en relación con los agregadores de noticias, incluida una intervención sobre los derechos".

El resultado ha sido la inclusión en la propuesta de Directiva de derechos de autor en el mercado único digital del artículo 11. Esta disposición reconoce a las editoriales de publicaciones de prensa el derecho a autorizar la reproducción y la puesta a disposición para el uso digital de esas publicaciones. Se trata de un derecho de veinte años de duración (a contar desde el momento de la publicación) que

47 Sobre el particular, véase "German publishers have filed complaint against Google: VG Media”, publicado en enero 2016, disponible en: http://www.reuters.com/article/ us-google-media-germany-iduskbnoujikf2oi6oros 
no afecta a los derechos correspondientes a los autores de los artículos de prensa como tales.

A mi modo de ver la regulación propuesta, salvo que sea objeto de modificación en el trámite legislativo que ahora comienza, va a tener una incidencia práctica limitada. La razón estriba en que, generalmente, en los contratos que las editoriales tienen con los periodistas (sean empleados o freelance), las primeras se reservan los derechos sobre sus contribuciones. Por lo tanto, los derechos que reconoce el artículo 11 , las editoriales ya los disfrutan... y por un periodo muy superior a veinte años (es decir, los setenta años que les otorga la protección por derecho de autor). Cuestión distinta hubiera sido que ese derecho se extendiera a "fragmentos no significativos de contenidos" (tal y como establece, p. ej., la legislación española). Como nada se dice al respecto, y puesto que las excepciones también se aplican a este derecho, cualquiera podrá seguir utilizando esos fragmentos sin precisar de autorización de las editoriales.

En definitiva, no parece que el nuevo derecho que se propone vaya a aliviar los problemas de las editoriales y a obstaculizar las actividades de los agregadores de contenidos.

\section{b. Hipervinculos y comunicación pública}

Resulta discutido si la introducción de un hipervínculo en un sitio web que enlace a un contenido en otro sitio web puede entenderse como un acto de comunicación pública. La cuestión reviste una gran relevancia para los PSI por cuanto la Directiva 2000/31 sobre comercio electrónico no establece ninguna exención de responsabilidad para los sitios web de enlaces -cosa que sí hacen las legislaciones de algunos Estados miembros.

Como se ha dicho, a pesar de mencionarlo en su Comunicación de 2015, finalmente la Comisión Europea ha decidido no introducir ninguna propuesta legislativa sobre el particular en la propuesta de Directiva sobre derechos de autor en el mercado único digital. Sin embargo, el TJuE ha tenido oportunidad de pronunciarse sobre esta cuestión en varias ocasiones ${ }^{48}$.

De esta jurisprudencia se puede concluir que el hipervínculo a obras que ya han sido puestas a disposición del público no puede considerarse como un acto de comunicación pública y, por lo tanto, no requiere la autorización del autor. En cambio, si el hipervínculo es a una obra que no ha sido puesta a disposición del público en general, se trata de un acto de comunicación pública que, de no mediar autorización del autor, constituye un acto infractor. En este sentido, en el supuesto típico de una persona que descarga ilegalmente una película de Netflix y la "sube" a Rapidshare poniéndola a disposición del público a través de un hi-

48 sstjue de 7 de marzo de 2013, C-607/11, "TVCatchup”, de 13 de febrero, C-466/12, "Svensson", de 23 de marzo de 2015, C-279/13, "C More Entertainment" y el auto de 21 de octubre de 2014, C-348/13, "Bestwater". 
pervínculo, nos encontramos con que está llevando a cabo actos de comunicación pública no autorizados.

Un supuesto diferente aparece cuando una persona X coloca un hipervínculo a unos contenidos albergados por otra persona Y que los había puesto a disposición del público sin autorización de su titular. Este fue el supuesto de la reciente STJUE de 8 de septiembre de 2016, C-160/15, "GS Media". La responsabilidad de Y resulta fuera de toda duda. No así la de X. El tjue entiende que en principio X no lleva a cabo un acto de comunicación pública pues resulta excesivo requerir a cualquier persona que actúa en internet que verifique la legalidad del contenido al que conduce un hipervínculo. Ahora bien, si X fuera un PSI que presta un servicio por el que genera unos ingresos económicos, se puede considerar que lleva a cabo un acto de comunicación pública si no verifica previamente la legalidad del contenido al que conduce el hipervínculo, o si, una vez notificado de su ilegalidad, no lo retira.

La interpretación adoptada por el TJUE en "GS Media" resulta controvertida: si existe comunicación pública debería existir en todos los supuestos. La regulación de este derecho en el artículo 3 de la Directiva 2001/29 no justifica un tratamiento diferente según si la persona que introduce el hipervínculo lleva a cabo una actividad económica o no.

Habrá que estar atento a las próximas sentencias del TJUE sobre la materia para saber si esta interpretación se consolida o no. En el momento actual hay dos casos pendientes sobre esta misma cuestión. En el primero, el asunto "Stichting Brein" 49 , se pregunta si la venta de un producto que contiene hipervínculos a contenidos no autorizados supone un acto de infracción, y si quienes comparten contenidos no autorizados deben considerarse infractores. En el segundo, el Tribunal Supremo neerlandés también ha preguntado al TJUE sobre la legalidad de compartir hipervínculos ".torrent" en un asunto que afecta al conocido portal "The Pirate Bay"

\section{c. El agotamiento "digital" del derecho de autor}

Otra cuestión que no ha recibido atención legislativa por la Comisión Europea es la referida al llamado agotamiento digital del derecho.

La sTjue de 3 de julio de 2012, C-128/11, "UsedSoft" estableció que la descarga de software desde un sitio web debía considerarse un acto de distribución a los efectos de la Directiva 2009/24 y que, bajo ciertas condiciones, el principio de agotamiento del derecho resultaba aplicable. Esta decisión parecía abrir la puerta a la aparición de lo que podría llamarse un mercado de productos digitales de segunda mano. Ahora bien, para que este mercado fructifique, resultaba preciso

49 Información obtenida de "Case C-527/15, Stichting Brein - copyright brain-teasers about media players”, disponible en: http://eulawradar.com/case-c-52715-stichting-brein-copyrightbrain-teasers-about-media-players/

50 Información obtenida de "Case C-610/15, Stichting Brein - seeking website blocks to stop peer to peer technology", disponible en: http://eulawradar.com/case-c-61015-stichtingbrein-seeking-website-blocks-to-stop-peer-to-peer-technology/ 
aclarar si la jurisprudencia "UsedSoft" resulta aplicable sólo en materia de software o también a cualquier contenido digital.

La sTjue de 22 de enero de 2015, C-419/13, "All Posters" parece dar a entender que, para el resto de obras, el derecho de distribución exige que la obra se ofrezca en "soporte tangible", con lo que se reduce enormemente el potencial de este mercado digital de productos de segunda mano. Por su parte, la reciente sTJue de 12 de octubre de 2016, C-166/15, "Ranks" viene a confirmar la aplicación del agotamiento del derecho de distribución a las copias originales de programas de ordenador (no así a las copias de salvaguardia que se puedan realizar de esos programas, incluso cuando el software original ha resultado dañado).

Teniendo en cuenta las importantes repercusiones de la decisión y las expectativas que levantó, era de esperar que el legislador europeo actuara. No obstante, ni la Comunicación de 2015 ni la de 2016 se refieren al mismo.

Ante esta circunstancia la cuestión debería haber quedado enterrada, si no fuera porque en la reciente sTjue de 10 de noviembre de 2016, C-174/15, "Vereniging Openbare Bibliotheken" se afirma que los libros electrónicos pueden ser objeto de préstamo público siempre que el usuario descargue la copia de la obra en su propio ordenador, pero sólo puede descargarse una copia durante el período de duración del préstamo, y una vez transcurrido ese período la copia descargada deja de ser utilizable. Aunque el TJUE aclara que la interpretación es únicamente aplicable al derecho de préstamo (y no, p. ej., al de alquiler) y que debe tratarse de copias lícitas de las obras, la decisión abre nuevas vías a los partidarios del agotamiento digital del derecho para defender su posición.

\section{Protección de los autores en sus relaciones Contractuales}

En su Comunicación de 2015, la Comisión Europea expresaba su preocupación por la justa remuneración de los autores y de los artistas intérpretes o ejecutantes, que pueden verse especialmente afectados por las diferencias en el poder de negociación a la hora de conceder licencias o ceder sus derechos ${ }^{51}$. La Comisión se comprometía a estudiar si se requieren soluciones a nivel de la UE para aumentar la seguridad jurídica, la transparencia y el equilibrio en el sistema que regula la remuneración de los autores y artistas intérpretes o ejecutantes.

Los análisis llevados a cabo por la Comisión han conducido a la incorporación de tres disposiciones (arts. 14 a 16) sobre esta cuestión en la propuesta de Directiva sobre derechos de autor en el mercado único digital.

La primera de ellas establece una obligación para los cesionarios de los derechos de informar periódicamente a los autores, artistas intérpretes y ejecutantes sobre la explotación de sus obras e interpretaciones, especialmente en lo que se refiere a los modos de explotación, los ingresos generados y la remuneración correspondiente. 
Se establecen excepciones a estas obligaciones para aquellos casos en los que los ingresos por explotación sean exiguos.

La segunda establece una facultad que ya se recoge, por ejemplo, en el ordenamiento alemán y español: el derecho del autor, intérprete o ejecutante "a solicitar una remuneración adecuada [...] en caso de que la remuneración inicialmente pactada sea desproporcionadamente baja en comparación con los ingresos y beneficios subsiguientes derivados de la explotación de las obras o interpretaciones".

La última establece la obligación para los Estados miembros de introducir sistemas alternativos para la resolución de las controversias que puedan surgir en relación con la regulación prevista en las dos disposiciones anteriores.

\section{EXCEPCIONES A LOS DERECHOS}

La regulación de las excepciones a los derechos ocupa una parte sustancial de la propuesta de Directiva de derechos de autor en el mercado único digital (arts. 3 a 6) y de la propuesta de Directiva sobre determinados usos permitidos de obras y otras prestaciones protegidas por derechos de autor en favor de personas con discapacidad visual.

Como es conocido, en el momento actual la D. 2001/29 contiene una lista cerrada de 20 excepciones, 19 de las cuales son opcionales. Si unimos el carácter opcional al hecho de que los avances tecnológicos han exigido una adaptación de estas excepciones por los legisladores nacionales, nos encontramos con un problema de inseguridad jurídica derivada de las divergentes normativas adoptadas. Esto afecta de lleno a la creación del mercado único digital, por lo que el deseo del legislador europeo de profundizar en la armonización de la regulación de varias excepciones resulta más que justificado.

Este deseo se ha visto plasmado en propuestas regulatorias de las siguientes excepciones: a) conversión de las obras a formatos accesibles para personas con discapacidad visual; b) minería de textos y datos; c) utilización de obras y otras prestaciones en actividades pedagógicas digitales y transfronterizas; d) conservación del patrimonio cultural.

Con carácter general, la regulación propuesta presenta una importante novedad en relación con la regulación actual contenida en el artículo 5 de la D. 2001/29: todas las excepciones propuestas son de obligado cumplimiento, no son opcionales para los Estados miembros. Esto asegura una regulación uniforme de las mismas en todo el territorio UE, incrementando presumiblemente la seguridad jurídica.

Infortunadamente, tal y como señalamos en el último epígrafe, son varios los aspectos relativos a las excepciones que finalmente no han sido objeto de una propuesta regulatoria. 


\section{a. Conversión de las obras a formatos accesibles para personas con discapacidad visual}

En primer lugar, como se ha explicado anteriormente, la UE tiene intención de ratificar el Tratado de Marrakech, circunstancia que implica la necesidad de llevar a cabo una actuación legislativa para adaptar las legislaciones sobre derechos de autor a los compromisos asumidos en dicho tratado.

En este sentido, la propuesta de Directiva sobre determinados usos permitidos de obras y otras prestaciones protegidas por derechos de autor en favor de personas con discapacidad visual plantea introducir una excepción a los derechos con el siguiente tenor (art. 3.1):

Los Estados miembros preverán que cualquier actuación necesaria para que:

a) un beneficiario o una persona que actúe en su nombre realice un ejemplar en formato accesible de una obra y otras prestaciones protegidas para uso exclusivo del beneficiario, $y$

b) una entidad autorizada realice un ejemplar en formato accesible y se lo transmita, facilite, distribuya o preste a un beneficiario o a una entidad autorizada para uso exclusivo de un beneficiario

no requiera la autorización del titular de los derechos de autor o derechos afines de la obra...

La propuesta no sólo servirá para cumplir con el mandato impuesto por el Tratado de Marrakech sino también para asegurar una regulación armonizada de la misma, por cuanto en el momento, aunque todos los Estados miembros tienes excepciones en esta materia, sus regulaciones son divergentes.

\section{b. Minería de datos (data mining)}

En su Comunicación de 2015, la Comisión Europea se planteaba presentar alguna propuesta legislativa en relación con la llamada minería de textos y datos (data mining), en virtud de la cual los ordenadores leen y analizan grandes volúmenes de contenidos digitales en el contexto de la ciencia y la investigación. Como explica la propia Comisión,

... la falta de disposiciones claras de la ue relativas a dicha minería con fines de investigación científica genera inseguridad en la comunidad investigadora. Ello redunda en perjuicio de la competitividad y el liderazgo científico de la uE en un momento en que las actividades de investigación e innovación ( $\mathrm{I}+\mathrm{i})$ deben realizarse cada vez en mayor 
medida a través de la colaboración transfronteriza e interdisciplinaria y a mayor escala, en respuesta a los grandes retos de la sociedad que aborda la I+i.

Finalmente, la excepción ha recibido la siguiente redacción en el artículo 3.1 de la propuesta de Directiva sobre derechos de autor en el mercado único digital:

Los Estados miembros establecerán una excepción a los derechos [...] con respecto a las reproducciones y extracciones realizadas por organismos de investigación con el fin de proceder a la minería de textos y datos de obras u otras prestaciones a las que tengan acceso legítimo con fines de investigación científica.

Debe observarse que el apartado 2 de la disposición establece, expresamente, que "será inaplicable toda disposición contractual contraria a la excepción prevista en el apartado 1". Se trata de una referencia que sólo encuentra una regulación similar en la Directiva 2009/24 sobre protección jurídica de los programas de ordenador (en relación con la excepción de descompilación) y la D. 96/9 de protección de las bases de datos. Esta excepcionalidad da fe de la importancia que la Comisión otorga a esta excepción en atención a los objetivos que con ella se persiguen.

\section{c. Utilización de obras y otras prestaciones en actividades pedagógicas digitales y transfronterizas}

Según se ha explicado anteriormente, en todos los Estados miembros se prevén excepciones para el uso de la obras con fines de ilustración en la educación y para fines de investigación. No obstante existen grandes diferencias regulatorias. En muchos casos con un grave impedimento a la enseñanza, sobre todo a distancia (por cuanto en muchos casos esas excepciones no están adaptadas al entorno digital) y más, si cabe, para proyectos educativos transfronterizos.

En su Comunicación de 2015, la Comisión Europea anunciaba la posibilidad de presentar propuestas legislativas para "aclarar el ámbito de aplicación de la excepción de la uE relativa a la 'ilustración con fines educativos' y su aplicación a usos digitales y al aprendizaje en línea”.

Finalmente, la excepción ha sido regulada en el artículo 4 de la propuesta de Directiva de derechos de autor en el mercado único digital. De acuerdo con su apartado 1:

Los Estados miembros establecerán una excepción o limitación a los derechos [...] a fin de autorizar el uso digital de obras y otras prestaciones únicamente con fines ilustrativos de enseñanza, en la medida en que ello esté justificado por la finalidad no comercial perseguida, siempre que el uso:

a) tenga lugar en los locales de un centro de enseñanza o a través de una red electrónica 
segura a la que solo puedan acceder los alumnos o estudiantes y el personal docente del centro;

b) vaya acompañado de la indicación de la fuente, con inclusión del nombre del autor, salvo que ello resulte imposible.

Como puede observarse, la excepción se refiere exclusivamente al "uso digital", por lo que las diferencias regulatorias en relación con el ejercicio de la excepción en el mundo analógico pueden perdurar. Además, los Estados miembros pueden establecer que la excepción no sea aplicable en general o con respecto a determinados tipos de obras en la medida en que estén fácilmente disponibles en el mercado licencias adecuadas que autoricen los actos cubiertos por la excepción. Del mismo modo, la disposición también habilita a los Estados miembros a prever una indemnización justa para los titulares de derechos por el perjuicio que les cause el ejercicio de la excepción.

Estas dos facultades que se ofrecen a los Estados miembros pueden provocar que las diferencias legislativas persistan. Si tenemos en cuenta que, según se ha explicado en otro apartado de este trabajo, a los efectos de esta disposición se considera que el ejercicio de la excepción tiene lugar en el Estado miembro de establecimiento del centro de enseñanza, se puede asistir a una competencia entre ordenamientos para atraer a centros de enseñanza que puede no ser muy beneficiosa para la protección de los derechos de autor.

\section{d. Conservación del patrimonio cultural}

Las tecnologías digitales ofrecen oportunidades a bibliotecas y archivos para cumplir con su función pública de difusión y preservación del conocimiento, que no existían en el momento en el que se adoptaron las excepciones existentes. A nivel europeo se tienen proyectos de digitalización masiva (la respuesta a Google Books) para los cuales se ha elaborado un modelo de Memorandum of Understanding $(\mathrm{MoU})$ sobre los principios fundamentales para la puesta a disposición de obras fuera de comercio acordado entre bibliotecas y archivos y entidades de gestión y editores. La idea es que estos libros que actualmente están en los archivos de bibliotecas se digitalicen y se pongan a disposición del público en general en el portal Europeana ${ }^{5}$. Según se ha explicado anteriormente, con este mismo objetivo, la propuesta de Directiva sobre derechos de autor en el mercado único digital establece un sistema de licencias multiterritoriales para la explotación de estas obras (arts. 7 y 8 ).

Además, la D. 2001/29 autoriza a los Estados miembros a adoptar excepciones para que las bibliotecas y archivos puedan llevar a cabo actos de preservación y

52 Disponible en: https://ec.europa.eu/digital-agenda/en/europeana-european-digitallibrary-all 
archivo de las obras, y consultas en sus establecimientos. ¿Pero hasta dónde alcanza la excepción?

En su Comunicación de 2015 la Comisión Europea anunció la posibilidad de presentar propuestas legislativas con el fin de:

a) proteger la conservación del patrimonio cultural por las instituciones, recogiendo el uso de las tecnologías digitales para la conservación y las necesidades de las obras creadas directamente en formato digital o digitalizadas; b) apoyar la consulta a distancia, en redes electrónicas cerradas, de las obras conservadas en bibliotecas académicas y de investigación u otras entidades pertinentes, para fines de investigación y estudio privado.

La propuesta finalmente presentada se refiere exclusivamente al primero de estos aspectos. De acuerdo con el artículo 5 de la propuesta de Directiva sobre los derechos de autor en el mercado único digital:

Los Estados miembros establecerán una excepción a los derechos [...] por la que se autorice a las instituciones de patrimonio cultural a efectuar copias de las obras u otras prestaciones que se hallen de forma permanente en sus colecciones, en cualquier formato y en cualquier soporte, con la única finalidad de conservar tales obras u otras prestaciones y en la medida necesaria para esa conservación.

\section{e. Cuestiones que no han sido objeto de propuestas legislativas}

Son varias las cuestiones relativas a las excepciones que, a pesar de ser mencionadas en la Comunicación de 2015, finalmente no han sido objeto de propuestas legislativas.

En primer lugar, en dicha Comunicación la Comisión Europea anunció que evaluaría "la necesidad de adoptar medidas relativas al canon por copia privada". Tras años de estudios, informes, mediaciones e innumerables decisiones del TJUE ${ }^{53}$, el anuncio de la Comisión sabía a poco. No obstante, la adopción de un régimen armonizado en esta materia resulta ciertamente complejo a la vista de las grandes diferencias regulatorias. Como indica la Comisión,

... los Estados miembros imponen cánones a veces con independencia de los pagos ya efectuados en otros Estados miembros, o sin que existan regímenes adecuados de exención o devolución. También pueden producirse pagos indebidos cuando se aplican cánones a productos de uso profesional. [...] También pueden existir prácticas discriminatorias en la distribución de los cánones recaudados, que favorezcan a los titulares de los derechos nacionales.

53 Asuntos cerrados: C-467/08, "Padawan”, C-462/09, "Thuiskopie”, C-277/10, "Luksan”, C-457/11 a C-460/11, "VG Wort", C-521/11, “Amazon” y C-435/12, “ACI Adam”, C-463/12, "Copydan", C-572/13, "Hewlett-Packard”, C-470/14, “Egeda”, y C-110/15, "Nokia Italia". 
Entre los temas que puede resultar necesario abordar figuran el vínculo entre compensación y perjuicio a los titulares de derechos, la relación entre los acuerdos contractuales y el reparto de los cánones, la duplicación de pagos, la transparencia de cara a los consumidores, las excepciones y los principios que rigen los sistemas de reembolso y la no discriminación entre nacionales y no nacionales en la distribución de los cánones recaudados.

La Comunicación de 2016 no indica si se tiene pensado realizar alguna actuación legislativa en un futuro próximo.

En segundo lugar, según se ha indicado anteriormente, la Comunicación de 2015 anunciaba la posibilidad de presentar propuestas legislativas para "apoyar la consulta a distancia, en redes electrónicas cerradas, de las obras conservadas en bibliotecas académicas y de investigación u otras entidades pertinentes, para fines de investigación y estudio privado". Finalmente, la propuesta de Directiva de derechos de autor en el mercado único digital no contiene ninguna referencia a la cuestión. La Comunicación de 2016 se limita a afirmar que "la Comisión seguirá evaluando la cuestión y que en un momento posterior puede ser oportuno reconsiderar la misma en atención a la jurisprudencia del TJUE". En particular, la Comisión se refiere al ya mencionado asunto C-174/15, "Vereniging Openbare Bibliotheken" referido al préstamo público de libros electrónicos. Pero este no es el único asunto en el que se pone de manifiesto la necesidad de regular esta cuestión. En el asunto que dio origen a la sTJuE 11 de septiembre de 2014, C-117/13, "Eugen Ulmer" se planteaba si, con base en la excepción de uso de obras y prestaciones protegidas a efectos de investigación o de estudio personal (art. 5.3 n) D. 2001/29), una biblioteca podía digitalizar obras para su consulta en terminales informáticas localizadas en sus instalaciones, y si los usuarios podía realizar copias de las mismas en dispositivos usB para la consulta de la obra digitalizada fuera del establecimiento. El TJUE respondió sí a la primera pregunta, y no a la segunda.

En tercer lugar, en las consultas realizadas por la Comisión Europea antes de 2015 se preguntaba por los retos regulatorios que presentaba el llamado contenido generado por los usuarios (User Generated Content o UGC). En muchos casos, este contenido es original, pero en otros está basado en copias preexistentes. En principio son actividades que precisarían de la autorización del autor, pero debe tenerse en cuenta que son actividades que las redes sociales y otras herramientas de internet han vuelto extremadamente generalizadas en la sociedad. Además, estas actividades de reutilización de las obras (para crear obras derivadas) no está limitada a unos pocos, sino que cualquiera lo puede llevar a cabo gracias a estas herramientas. En fin, a la hora de fijar el carácter ilícito o no de estas actividades debe tenerse presente la libertad de expresión como counterbalance al derecho del titular de la obra.

Las nuevas herramientas tecnológicas y las redes sociales también conllevan un cambio en los hábitos sociales de los ciudadanos en relación con la manera en que estos crean, consumen e interactúan con contenidos. 
Infortunadamente, la adaptación del régimen de los derechos de autor a estos nuevos hábitos deberá esperar un mejor momento o, en su caso, deberá realizarse jurisprudencialmente. La propuesta de Directiva no establece nada al respecto. La única actuación que la Comisión europea ha acometido es la consulta pública sobre la llamada "libertad de panorama", excepción que permite la utilización de obras concebidas para estar situadas de forma permanente en el espacio público. Con ello se exime de responsabilidad a las personas que toman fotografías de, por ejemplo, la torre de Pisa y las utilizan exclusivamente para subirlas a Facebook, es decir, sin ningún interés comercial.

Sobre el particular, la Comisión explica en su Comunicación de 2016:

Después de un análisis de los resultados de la consulta pública acerca de la excepción de la "libertad de panorama" [...], la Comisión confirma la pertinencia de esta excepción. Según la legislación de la UE, los Estados miembros disfrutan de un amplio margen de maniobra para establecer estas excepciones. Casi todos los Estados miembros tienen una excepción de panorama en su legislación nacional. Recientemente, algunos Estados miembros que todavía no lo habían hecho, han introducido esta excepción en sus ordenamientos o debatido proyectos de medidas en tal sentido. La Comisión recomienda que los Estados miembros apliquen esta excepción; seguirá de cerca la evolución de esta cuestión.

Ciertamente, el avance jurisprudencial del que hablamos en el párrafo anterior sería más sencillo si la legislación europea de derechos de autor contara con una cláusula de "fair use". De hecho, muchos nos preguntamos si no ha llegado el momento de acabar con la lista tasada de excepciones, e introducir una cláusula abierta de usos honrados. Por desgracia la cuestión, que sí se planteaba la europarlamentaria Julia Reda en su Borrador de Resolución, ni tan siquiera se plantea por parte de la Comisión.

\section{Observancia de los Derechos}

Como bien afirma la Comisión Europea, "un derecho que no se puede hacer cumplir de forma efectiva tiene poco valor económico".

La normativa europea en materia de observancia de los derechos de propiedad intelectual está incluida básicamente en la Directiva 2004/48, la cual adaptó al derecho ue las obligaciones establecidas en la Parte III del Acuerdo ADPIC. Mucho ha llovido desde entonces y, por ello, la Comisión lanzó en 2015 una consulta pública sobre una posible actualización de la Directiva, por cuanto "el marco jurídico actual no parece idóneo para los retos del mercado único digital, en particular en lo que se refiere a la aplicación del derecho de información, las acciones de cesación y su efecto transfronterizo, el cálculo de los daños y perjuicios y el reembolso de las costas procesales". 
Dicha actualización debería prever medidas penales de protección de los derechos de propiedad intelectual. La Comisión propuso una directiva en la materia por primera vez en 2005, pero fue rechazada por falta de base jurídica. Tras la adopción del Tratado de Lisboa dicho problema ya no existe pues las instituciones han sido dotadas de las competencias necesarias ${ }^{54}$. El problema residirá en lograr que la legislación propuesta establezca un equilibrio adecuado entre la protección de los derechos de propiedad intelectual y los derechos y libertades fundamentales de los ciudadanos europeos establecidos en la Carta de Derechos Fundamentales. Por el momento no se ha propuesto ninguna legislación en este sentido, y ni la Comunicación de 2015 ni la de 2016 la plantean.

En relación con la observancia de los derechos en el entorno digital, debe recordarse que la Directiva 2000/31 sobre comercio electrónico y la Directiva 2001/29 se limitan a establecer una obligación genérica de los prestadores de servicios de cooperar con las autoridades en la prevención o sanción de las infracciones cometidas por los usuarios. Esto ha dado lugar a que cada Estado miembro haya adoptado sistemas diferentes de desarrollo de esta obligación genérica. En la Comunicación de 2015, la Comisión Europea plantea la adopción de medidas a nivel europeo en dos sentidos.

Por un lado, la adopción del método de follow the money ("seguir la pista del dinero"), que consiste en adoptar medidas -ya sean legislativas o de autorregulación del sector-para privar a quienes cometan infracciones comerciales de los flujos de ingresos (p. ej., de los pagos de los consumidores y la publicidad) procedentes de sus actividades ilegales, teniendo, por lo tanto, un efecto disuasorio ${ }^{55}$. Uno de los Estados donde ya está vigente este método es España, cuyo artículo $158 \operatorname{ter} 5$ LPI que establece que ante la falta de retirada de unos contenidos ilícitos por parte de un PSI, la Sección Segunda de la Comisión de Propiedad Intelectual podrá "requerir la colaboración necesaria de los prestadores de servicios de intermediación, de los servicios de pagos electrónicos y de publicidad, requiriéndoles para que suspendan el correspondiente servicio que faciliten al prestador infractor".

El problema de una regulación como la española es el siguiente: para acelerar la tramitación de las reclamaciones de retirada o bloqueo de contenidos se ha otorgado la competencia a una autoridad administrativa (la Sección Segunda) que, como tal, sólo tiene competencia sobre el territorio español. Por ello, resulta imposible para la Comisión -a expensas de ser declaradas nulas por falta de competencia territorial- emitir órdenes de retirada o bloqueos de sitios web, o de identificación de titulares de páginas web a PSI establecidos en otros Estados miembros. Para solventar este problema no hay más remedio que adoptar algún tipo de regulación

54 Art. 83 TFue.

55 En el momento de cerrar el presente trabajo se había publicado en el sitio de internet Edri-gram una filtración del borrador del documento de la Comisión "The Follow the Money Approach to IPR Enforcement - Stakeholders' Voluntary Agreement on Online Advertising and IPR Guiding Principles", disponible en: https://edri.org/files/guiding_principles_follow_the_money_approach_ipr_enforcement.pdf 
europea que facilite la cooperación entre autoridades administrativas o judiciales para hacer cumplir estas órdenes.

Por otro lado, la posible introducción de mecanismos de "notificación y retirada" (en Europa llamados de "notificación y acción"), si bien no se indica si los mismos deben ser una obligación para los Psi o si deben adoptarse a partir de códigos de conducta consensuados entre organismos de representación de las partes implicadas: PSI, por un lado, y usuarios, por otro. Debe recordarse que, por el momento, en la UE sólo existe una obligación para los Estados miembros de fomentar este tipo de mecanismos de resolución de disputas (art. 16 Directiva 2000/31), pero en la práctica esto no ha conllevado una adopción generalizada de estos mecanismos por parte de los PSI.

Ninguno de estos dos mecanismos se ha visto plasmado, por ahora, en propuestas legislativas. En su Comunicación de 2016 la Comisión indicaba que todavía estaba "llevando a cabo una evaluación del funcionamiento global del marco jurídico vigente en cuanto a la aplicación efectiva de los DPI".

Así las cosas, la propuesta de Directiva de derechos de autor en el mercado único digital introduce una única norma que podría entenderse relacionada con la observancia de los derechos. Se trata del artículo 13, cuyos destinatarios son los "proveedores de servicios de la sociedad de la información que almacenen y faciliten acceso público a grandes cantidades de obras u otras prestaciones cargadas por sus usuarios" (léase YouTube, Rapidshare y similares).

De acuerdo con esta disposición, estos proveedores deben adoptar, con la ayuda de los titulares de derechos, medidas para: a) garantizar que se respetan los acuerdos celebrados con dichos titulares para la divulgación de sus obras; b) impedir que estén disponibles en sus servicios obras u otras prestaciones identificadas por los titulares de los derechos para cuya divulgación no se tiene autorización. Entre las medidas a adoptar se habla de "técnicas efectivas de reconocimiento de contenidos".

Por último, se insta a los Estados miembros a velar por que proveedores y titulares de derecho cooperan en el establecimiento de esas medidas; y a que los proveedores implantan mecanismos de reclamación y recurso (notice and takedown) a los que puedan acceder los usuarios en caso de litigio sobre la aplicación de esas medidas.

\section{CONCLusiones}

El proceso de reforma del sistema de derechos de autor en la Unión Europea confirma una máxima inquebrantable en la propiedad intelectual: no existe un modelo de protección de la propiedad intelectual válido con carácter general. Cada Estado debe adaptar su sistema de propiedad intelectual a sus características particulares. En este sentido, las soluciones propuestas por la Comisión Europea son exclusivas de una organización de integración económica como la uE de la que forman parte 28 Estados miembros, con 28 leyes diferentes de derechos de autor. 
Estamos de acuerdo con la Comisión Europa en que, en el momento actual, el proyecto de crear un código europeo único de derechos de autor es inviable. Por ello, el recurso a mecanismos alternativos que ha dado buenos resultados en otras materias es acertado.

En primer lugar, en relación con el binomio control en origen-reconocimiento mutuo, debe aplaudirse la propuesta de extender su aplicación a los servicios accesorios en línea de organismos de radiodifusión y distribución por cable; la utilización de obras y otras prestaciones en actividades pedagógicas digitales y transfronterizas; y el intercambio transfronterizo de ejemplares de obras en formato accesible para personas con discapacidad visual. A nuestro modo de ver, resulta posible extender la aplicación de este mecanismo a otras cuestiones, pero debe aplaudirse la decisión de la Comisión de ir poco a poco y no pecar de ambición excesiva.

En segundo lugar, la extensión de los sistemas de licencias multiterritoriales abierta por la Directiva 2014/26 y que pretende extenderse a la digitalización de obras fuera de comercio por parte de instituciones de patrimonio cultural también puede ofrecer buenos resultados para acabar con la fragmentación del mercado único digital. En este mismo sentido, es de aplaudir la propuesta de Reglamento por el que se castigan las prácticas de geobloqueo. Bien es cierto que la creación de un mercado único digital exigirá ir un paso más allá y permitir que los usuarios puedan elegir el prestador con el que contratan con independencia de su residencia habitual.

En tercer lugar, no puede criticarse que la Comisión Europea siga utilizando como mecanismo prioritario el de la armonización de legislaciones. La armonización de ciertos aspectos regulatorios es el paso previo para poder implementar los otros dos mecanismos y, sobre todo, para llegar al título unitario en materia de derechos de autor. Dicho mecanismo está presente particularmente en la propuesta de Directiva sobre los derechos de autor en el mercado único digital. No obstante, esta propuesta presenta dos características que la diferencian de directivas precedentes. Por un lado, ya no es una directiva "de mínimos" en la que se permite a los Estados miembros introducir un nivel de protección más elevado de los derechos. Por otro, las excepciones dejan de ser opcionales. Los Estados miembros están obligados a incorporarlas a sus ordenamientos tal y como se establece en la Directiva. Ambas características responden a un objetivo: garantizar la seguridad jurídica de los operadores en el mercado único digital eliminando, en la medida de lo posible, las divergencias legislativas. A nuestro modo de ver, el nuevo enfoque resulta acertado. El tiempo dirá si con ello se alcanza el objetivo de crear el ansiado mercado único digital.

\section{BibliografÍA}

Comunicación "Hacia un marco de derechos de autor moderno y más europeo", Doc. $\operatorname{com}(2015) 626$ final. 
Comunicación "Promover una economía europea basada en los derechos de autor equitativa, eficiente y competitiva en el mercado único digital", Doc. $\operatorname{com}(2016) 592$ final.

Comunicaciones y documentos de trabajo de la Comisión Europea.

Propuesta de Directiva sobre ciertos usos autorizados de las obras y otras prestaciones protegidas por los derechos de autor y derechos afines a los derechos de autor en beneficio de las personas ciegas, con discapacidad visual o con otras dificultades para acceder al texto impreso, Doc. Сом(2016) 596 final.

Propuesta de Directiva sobre derechos de autor en el mercado único digital, Doc. $\operatorname{Com}(2016) 593$ final.

Propuesta de Reglamento para asegurar la portabilidad transfronteriza de los servicios de contenidos en línea en el mercado interior, Doc. Сом(2015) 627 final.

Propuesta de Reglamento por el que se establecen normas sobre el ejercicio de los derechos de autor y derechos afines a los derechos de autor aplicables a determinadas transmisiones en línea de los organismos de radiodifusión y a la retransmisión de programas de radio y televisión, Doc. сом(2016) 594 final

Propuesta de Reglamento sobre el intercambio transfronterizo entre la Unión y terceros países de ejemplares en formato accesible de determinadas obras y otras prestaciones protegidas por derechos de autor y derechos afines a los derechos de autor en beneficio de las personas ciegas, con discapacidad visual o con otras dificultades para acceder al texto impreso, Doc. Сом(2016) 595 final.

\section{JURISPRUDENCIA}

Auto TJue de 21 de octubre 2014, C-348/13, "Bestwater".

Conclusiones del Abogado General de 8 de septiembre 2016, Dictamen 3/15,

"Tratado de Marrakech".

STJUE de 10 de noviembre de 2016, C-174/15, "Vereniging Openbare Bibliotheken". STJUE de 11 septiembre de 2014, C-117/13, "Eugen Ulmer".

STJUE de 12 de octubre de 2016, C-166/15, "Ranks".

sTjue de 13 de febrero de 2014, C-466/12, "Svensson". stjue de 21 de junio de 2012, C-5/11, "Titus Donner".

STJUE de 21 de octubre de 2015, C-347/14, "New media online".

stjue de 22 de enero de 2015, C-419/13, “All Posters".

stjue de 23 de marzo de 2015, C-279/13, "C More Entertainment".

stjue de 3 de julio de 2012, C-128/11, "UsedSoft".

STJue de 4 de octubre de 2011, C-403/08 y C-429/08, “FAPL”.

sTJue de 7 de marzo de 2013, C-607/11, “TVCatchup".

stjue de 8 de septiembre de 2016, C-160/15, "GS Media". 